Türkiye Jeoloji Bülteni
Geological Bulletin of Turkey
$60(2017) 313-330$
doi:10.25288/tjb.325401

\title{
Şeyhler Yöresi Borat Yatağının Jeokimyasal Özellikleri, Emet, Türkiye
}

Geochemical Properties of the Şeyhler Borate Deposits (Emet, Turkey)

\section{İsmail Koçak (D)}

\author{
Bozok Üniversitesi Mühendislik-Mimarlık Fakültesi Jeoloji Mühendisliği Bölümü, \\ Atatürk Yolu 66900 Yozgat
}

Geliş̧/Received : 06.03.2017 • Düzeltilmiș Metin Geliş/Revised Manuscript Received : 20.04.2017 • Kabul/Accepted : 28.04.2017 • Bask1/Printed : 01.08 .2017 Araştırma Makalesi/Research Article Türkije Jeol. Bül. / Geol. Bull. Turkey

Öz: Batı Anadolu borat yatakları Paleojen'de başlayan ve Kuvaterner başlangıcına kadar devam eden volkanik aktivitelerin yer aldığı dönemlerde Miyosen kıta-içi playa-göl çökelleri içinde depolanmıştır. Cevher oluşumlarının tamamı volkanik aktivite ile ilgilidir. Emet Şeyhler yatağında Ca yerkabuğu ve andezit ortalamasına göre artış göstermiştir. Eser elementlerden $\mathrm{As}, \mathrm{Se}, \mathrm{Cs}, \mathrm{Li}$, Sr ve Sb zenginleşmeleri belirlenmiştir. Konsantrasyonlarına göre Se ve Li elementlerinin B'un yanında yan ürün olarak ekonomiye kazandırılabileceği sonucuna varılabilir. Yatakta elementler iki grup halinde kümelenmiştir. $\mathrm{Si}, \mathrm{Mg}, \mathrm{Al}, \mathrm{Fe}$ ve $\mathrm{K}$ gibi elementlerden oluşan büyük grup ve $\mathrm{B}, \mathrm{Ca}$ ve $\mathrm{Na}$ 'dan oluşan ikinci grup şeklindedir. NTE dağılım diyagramlarında görülen $\mathrm{Ce}$ ve Eu anomalileri, yatakların yüksek oksijenli ve hidrotermal katkılı ortamda oluştuğunu ortaya koymuştur.

Anahtar Kelimeler: Bor, element korelasyonu, jeokimya, mineraloji, NTE

Abstract: Borate deposits of western Anatolia were formed in the intra-continental playa lake sediments during Miocene when the volcanic activity occurred from Paleogene to Quaternary. All mineralizations are associated with these volcanic activities. The main element $\mathrm{Ca}$ in Emet Seyhler deposits shows enrichment compared to the averages of Earth crust and andesite. The trace elements of Se, Sr, As, Sb, Mo and Li in borate deposits enrichments are determined. It can be concluded that based on the concentration of Se and Li elements could be recovered as by product, besides B. Elements in deposits are clustered in two groups. A large group consists of elements such as Si, $\mathrm{Mg}, \mathrm{Al}, \mathrm{Fe}, \mathrm{K}$ and a second group composes of B, Ca and Na. According to Ce and Eu anomalies observed in the REE distribution diagrams show these deposits should have formed under highly oxidative conditions with significant hydrothermal contribution.

Key Words: Borate, element correlation, geochemistry, mineralogy, REE 


\section{GíRiș}

Dünya borat rezervinin yaklaşı \%72'si Türkiye'nin batısında bulunmaktadır. Son yıllarda bilinen yatakların dışında Hisarcık ilçesinin yaklaşık $8 \mathrm{~km}$ güneybatısında Emet bölgesinde Şeyhler köyü civarında yeni bir yatak da tespit edilmiştir (Şekil 1). aldığı dönemlerde Miyosen gölsel ortamlarda depolandığını ortaya koymuştur. Bilinen borat yatakları ile ilgili ana ve eser element ve NTE içerikleri ile ilgili bazı çalışmalar da yapılmıştır (İlhan, 2006; Koç vd. 2008a, 2008b, 2017; Koçak ve Koç, 2009, 2011, 2012a, 2012b, 2016). Ancak Emet Şeyhler boratlarının ana ve eser

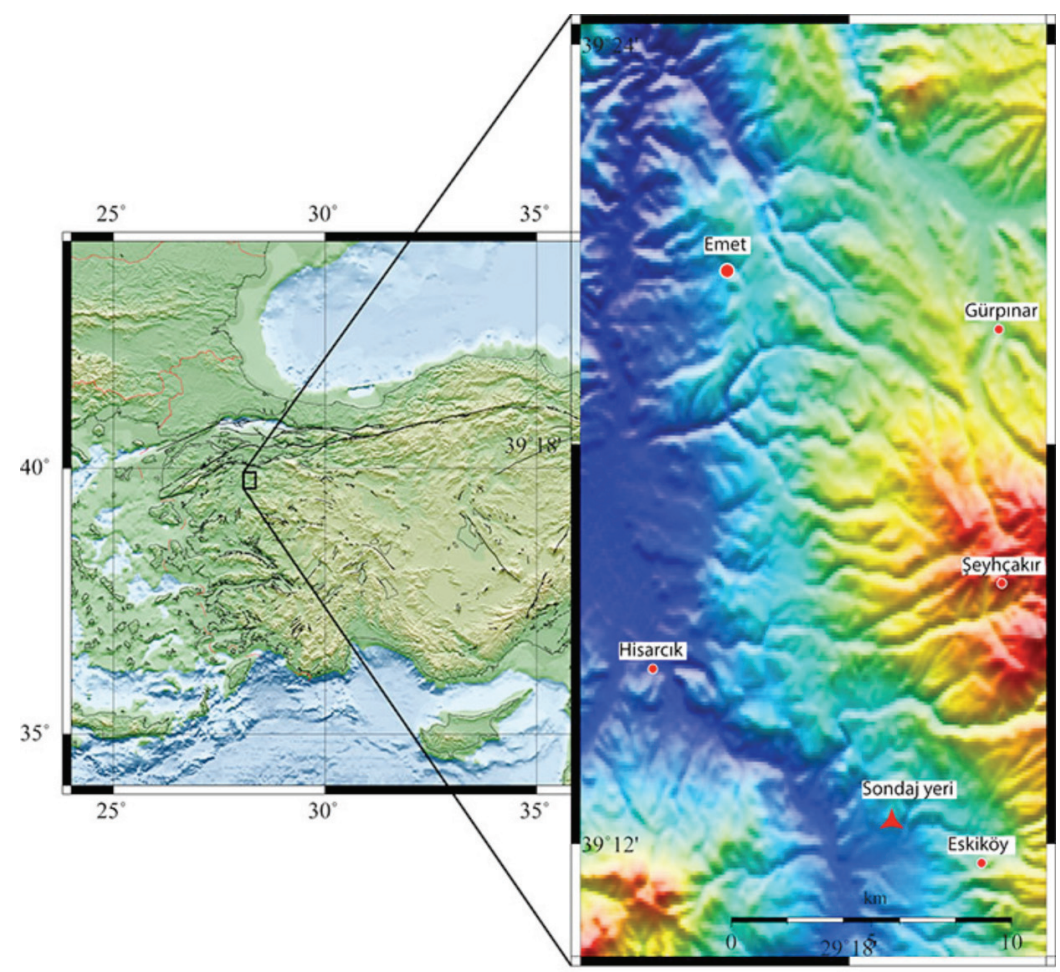

Şekil 1. Emet Şeyhler borat yatağının yer bulduru haritası

Figure 1. Location map of Emet Şeyhler borate deposits

Emet bölgesinde bilinen yataklar, genel jeolojik ve mineralojik olarak birçok araştırmanın konusu olmuştur (Gawlik, 1956; Özpeker, 1969; İnan, 1975; Yalçın vd. 1985; Floyd vd. 1997; Helvac1 ve Orti, 1998; Helvac1, 2004; Özkul, 2008; Hatipoğlu, 2010; Erdem, 2010; Garcia vd. 2010a, 2010b; Garcia vd. 2011; Helvac1, 2015a; Helvac1, 2015b, Cooper vd. 2015; Özkul vd. 2017). $\mathrm{Bu}$ çalışmalar Emet bölgesi borat yataklarının, Paleojen'de başlayan ve Kuvaterner başlangıcına kadar devam eden volkanik aktivitelerin yer element içerikleri ve değerlendirmeleri daha önce yeterince detaylı olarak çalışılmamıştır. Oysa ana ve eser element jeokimyas1, bir maden yatağının tanımlanmasında çok önemli veriler sunabilmektedir. Bir maden yatağını tanımlarken onun içerdiği ve zaman zaman ihmal edilen eser elementlerin varlığ 1 ve bolluğunun göz önüne alınması bilimsel bir gerekliliktir. Günümüzde birçok eser element bir maden yatağını oluşturan ana element ve/veya elementlerden daha önemli hale gelebilmektedir. Ayrıca bir maden yatağında 
bulunan ancak ekonomik ve teknolojik şartlar gereği bugün elde edilmesi imkânsız gibi görünen elementlerin gelişen imkânlarla elde edilip, zenginleştirilebileceği göz ardı edilmemelidir. $\mathrm{Bu}$ sebeple önemli görülmüş ve bu çalışmada ana ve eser element incelemeleri üzerinde yoğunlaşılmıştır.

$\mathrm{Bu}$ kapsamda esas olarak borat oluşum sürecinde etkin olan beslenme ve çökelme ortamı koşulları, çalışma alanındaki boratların ana ve eser element içeriklerinin jeokimyasal verilerin değerlendirilmesi ile yapılmıştır. Bunun için öncelikle boratların içerdiği ana, eser element ve NTE bollukları ve zenginleşmeleri araştırılmıştır. Ana ve eserelementler arasındaki korelasyonlardan yararlanarak elementlerin kökensel ilişkileri; NTE bollukları ve anomalileri kullanılarak ortamın çökelme koşulları belirlenmeye çalışılmıştır.

\section{MATERYAL VE YÖNTEM}

Araştırmanın materyalini Şeyhler yatağını temsil eden Etibank Emet Bor İşletme Müdürlüğü tarafından yapılmış olan BME 2007/7 nolu sondajdan alınan borat örnekleri oluşturmaktadır. 188 ile $250 \mathrm{~m}$ derinlikler arasinda derlenen 18 adet İS kodlu örnekte jeokimyasal analiz yapılmıştır. Jeokimyasal analiz öncesinde örneklerden killeri uzaklaştırmak amaciyla her biri basınçlı hava ile temizlenmiş ve daha sonra yıkanmıştır. Analizler Automaticity in Cognition Motivation \& Evaluation (ACME) Laboratuvarlarında yapılmıştır. Çalışmanın konusu olan nadir toprak elementleri Inductively Coupled Plasma-Mass Spectrometry (ICP-MS) yöntemiyle, ana ve eser elementler ise Inductively Coupled Plasma- Emission Spectroscopy (ICPES) ile analiz edilmiştir. $\mathrm{B}_{2} \mathrm{O}_{3}$ analizi Bozok Üniversitesi Bilim ve Teknoloji Uygulama ve Araştırma Merkezi'nde (BİLTEM) Thermo Scientific ARL Perorm'x Dalga Boyu Dağılımlı X-1şını Floresans (WD-XRF) Spektrometresi ile yapılmıştır. Mineralojik incelemelerde mikroskop yanında X-1şını difraktometresi (XRD) ve Konfakol Raman yönteminden de yararlanılmıştır. XRD yönteminde killer oluklu camlar üzerine sıvamayla yönlendirilmiş kil paketleri şeklinde hazırlanarak normal, etilen glikollü ve fırınlama koşullarında ayrı ayrı analiz edilmiştir. XRD incelemeleri Türkiye Petrolleri Anonim Ortaklığg (TPAO) Laboratuvarlarında Rigaku D marka Max 2200 Ultima/Pc cihazında ve Cu-tüpü, 40 $\mathrm{Kv}, 20 \mathrm{~mA}, 1,54059 \mathrm{~A}^{0}(\mathrm{CuK} \alpha 1)$ dalga boyu ve $2 \%$ dk tarama hızı aletsel koşullarda yapılmıştır. Son olarak, örneklerde uygulanan Raman yöntemi ise A.Ü Yer Bilimleri Uygulama ve Araştırma Merkezi (YEBİM)'nde Olympus BX41 model Konfakol Raman Spektrometre cihazında gerçekleştirilmiştir.

\section{JEOLOJİK KONUM}

Çalışmada borat yatağı ve çevresinin jeolojisi Özkul (2008)'den yararlanılarak özetlenmiştir. Emet baseni ve yakın çevresinde, Miyosen öncesi temel kayaçlarının (Helvacı, 1977; Yalçın, 1984) üzerindeki birimler sırasıyla Sarıcasu formasyonu (şişt), Arıkaya formasyonu (kristalize kireçtaşları), Budağan kireçtaşı ve Eğrigöz granitoyitlerinden oluşmaktadır (Akdeniz ve Konak, 1979). Bu birimlerin üzerinde alttan üste doğru Neojen yaşlı Taşbaşı formasyonu (Çakıltaşı-kumtaş1) (Akdeniz ve Konak, 1979), Köprücek felsik taban volkanitleri (Özkul, 2008), Taban Çökelleri [Karbasan formasyonu (kçt) (Dündar vd., 1986), Yeniceköy plaket kireçtaşları (Özkul, 2008), Beyköy formasyonu (çakıltaşı, kumtaşı) (Yalçın, 1984), Ergünler taban kireçtaşları (Özkul, 2008), İğdeköy formasyonu (Özkul, 2008)], Tavan Çökelleri [Emet örtü kireçtaşları (Özkul, 2008), Merkezşıhlar formasyonu (kumtaşı) (Yalçın, 1984)] ve Dereköy mafik tavan volkanitleri (Yalçın, 1984; Özkul, 2008) gelmektedir. Neojen birimleri üzerinde ise Kuvaterner yaşlı traverten, eski nehir taraçaları ve alüvyonlar yer almaktadır (Şekil 2). 


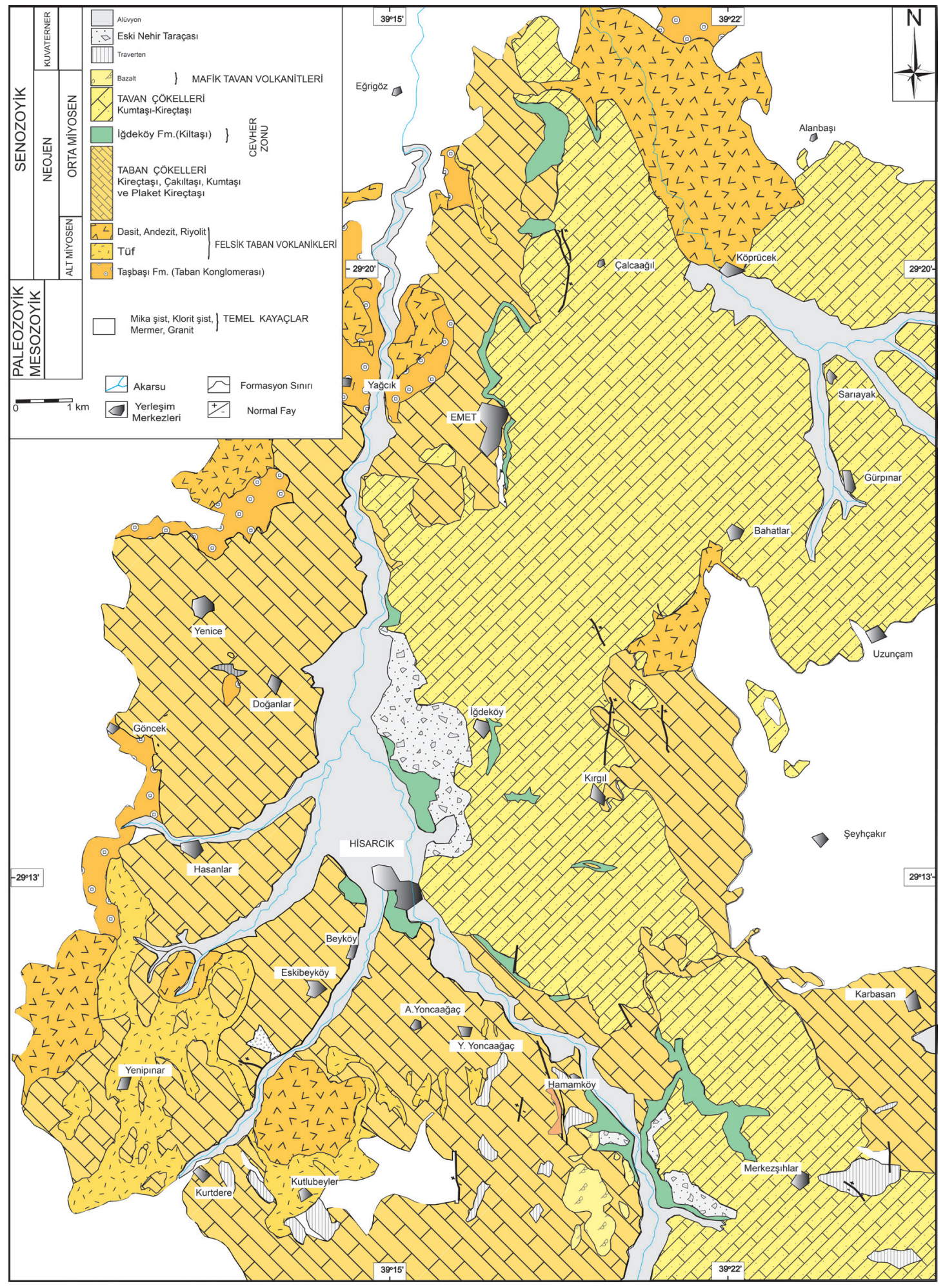

Şekil 2. Emet borat yatağı ve çevresinin jeolojik haritası (Özkul 2008'den sadeleştirilmiştir)

Figure 2. Geology map of Emet borate deposit and its surroundings (simplified from Özkul 2008). 
Bor seviyelerini içeren İğdeköy formasyonunda yeşil renkli yarı pekişmiş kiltaşı ve silttaşı egemen olup, içerisinde az oranda tüf ve ince kireçtaşı-marn ara tabakaları da içermektedir. İğdeköy formasyonu, İğdeköy ve Hamamköy'ün D'su, Hisarcık'ın KD'su, Merkez şeyhler ve civarı ile Killik mevkiinde dar bir alanda yüzeylemektedir. Formasyonun kalınlığı önceki araştırmacılara göre 30-450 m arasında değişmektedir (Özpeker, 1969; Helvacı, 1977; Akdeniz ve Konak, 1979; Yalçın, 1984; Yalçın vd. 1985; Dündar vd. 1986; Özkul, 2008).

İğdeköy formasyonu; Ergünler taban kireçtaşlarının üzerine kiltaşı, marn ve ince tabakalı kireçtaşı seviyeleri ile uyumlu olarak gelir ve üste doğru bor merceklerini de içeren yeşilimsi tüf ara katkılı killi seviyelere geçer. Tabandan tavana doğru koyu yeşil ve koyu gri renklere doğru değişim gösteren, yağımsı ve cilalı pırıltılı bir görünüm sunan killerin montmorillonit ve illit türünde olduğu belirtilmiştir (Helvacı ve Firman, 1977; Yalçın ve Gündoğdu, 1985; Dündar vd. 1986; Yalçın ve Gündoğdu, 1987). Killer genellikle kolemanit yumrularının etrafını bir film şeklinde sarmaktadır. Kolemanit yumrularının çapı 5-60 cm boyutlarına ulaşabilmekte ve ışınsal bir görünüm sunmaktadır. Arsenikçe zengin olduğu bilinen kiltaşı, birkaç düzeyde $5-10 \mathrm{~cm}$ çapında realgar ve orpiment mineralleri bulundurur. İstifin üst kısımlarda ise hakim olarak marnlı seviyeler mevcuttur. Marnlar tabandan tavana yeşilden kirli beyaz ve griye doğru renk farklılı̆̆ gösterirken ayrıca toprağımsı yapıda, turbalı ve kolemanit yumruludur. Hem kil, hem de marn seviyeleri organik maddece zengindir (Özkul, 2008).

\section{ANALITIIK VERILER VE TARTIŞMA}

\section{Borat Cevherleşmesinin Mineralojisi}

EmetŞeyhler boratyatağının mineralojisi polarizan mikroskop, Konfakol Raman spektroskopisi ve X-1şını difraktometresi (XRD) yöntemleri kullanılarak incelenmiştir. Karot örneklerinde kolemanit mavimsi tonda, hidroborasit ise koyu sarımsı ve kahve renklerde gözükmektedir (Şekil 3a). Üleksit ise sarımsı beyaz renkli olup ışınsal yapısı belirgindir (Şekil 4a).

\section{Mikroskop incelemeleri}

Kolemanitin mikroskop görüntüsü tek nikolde sarımsı beyaz renkte, çapraz nikolde ise ikinci dizi ortası girişim rengi göstermektedir (Şekil 3b). Hidroborasit de kolemanit gibi sarımsı beyaz renkte, çapraz nikolde ise ikinci dizi ortası girişim rengi göstermektedir (Şekil 3b). Üleksit ise 1şınsal büyümüş olup, kristaller birbirinden bağımsızdır. Tek nikolde kirli beyaz-gri, çapraz nikolde ise yeşil, turuncu, gri mavi ve pembe renklerde canlı girişim renkleri göstermektedir. (Şekil 4b). 


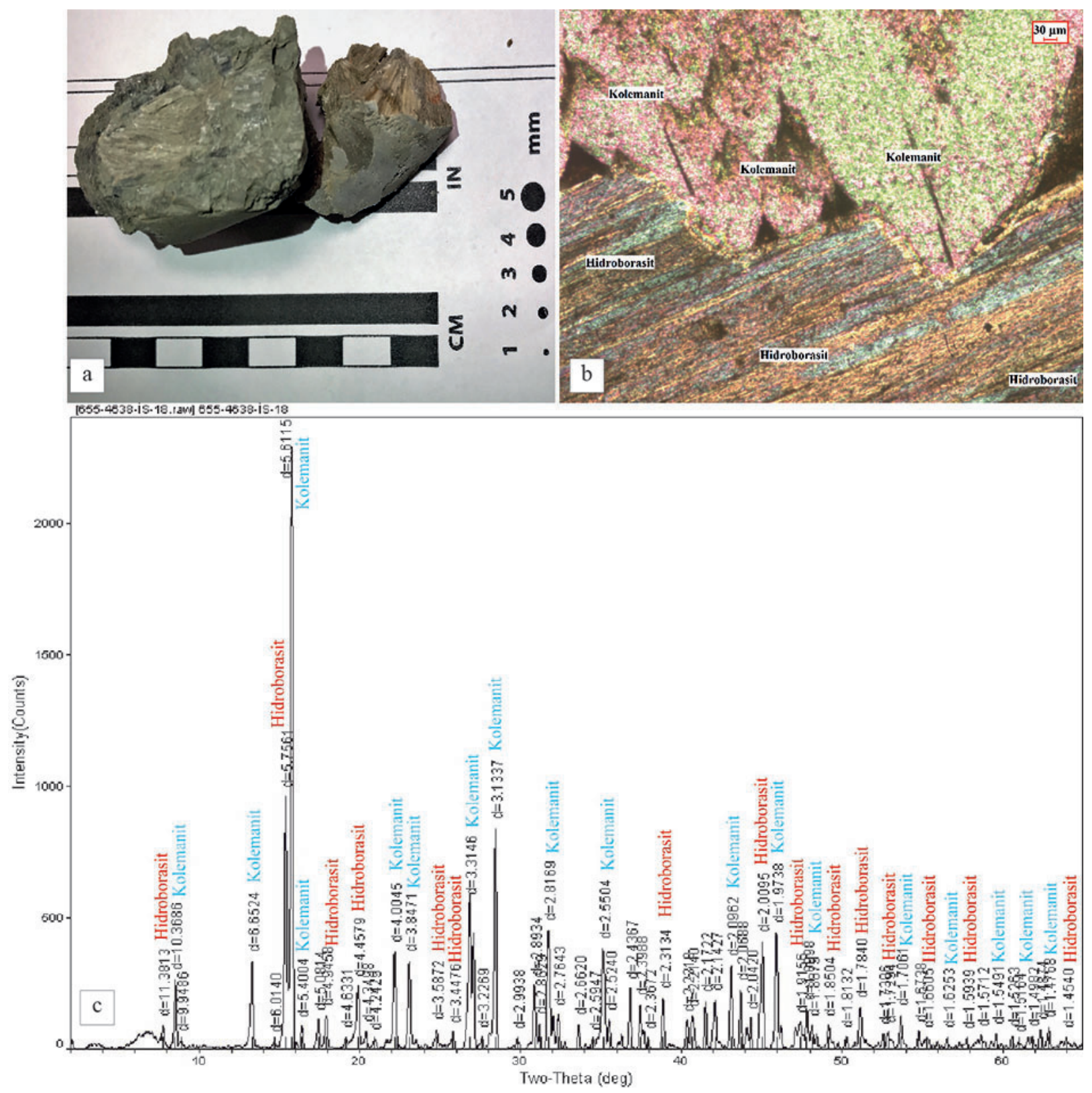

Şekil 3. (a) Işınsal hidroborasit ve kristal kolemanit, (b) Kolemanit ve hidroborasit çapraz nikol altında, (c) Kolemanit ve hidroborasite ait X-ray kırınım grafiği

Figure 3. (a) Radial hydroboracite and crystal colemanite, (b) Cross nicol view of hydroboracite and colemanite, (c) $X$-ray diffraction graph of hydroboracite and colemanite. 


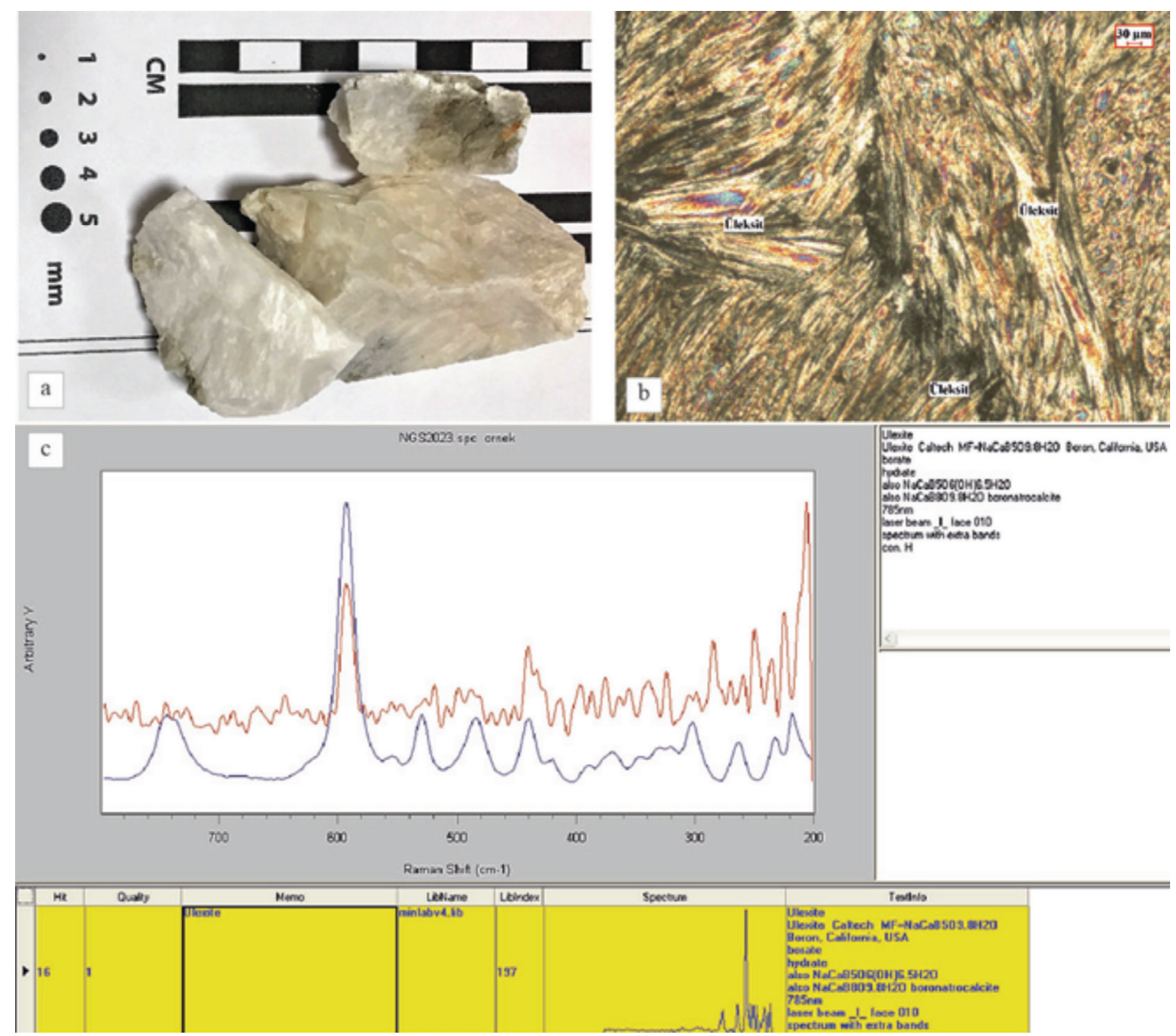

Şekil 4. (a) Işınsal üleksit, (b) Üleksitin çapraz nikol altındaki görüntüsü, (c) Üleksite ait Raman Spektrumu Figure 4. (a) Radial ulexite, (b) Cross nicol view of ulexite, (c) Raman spectrum of ulexite peak.

\section{Konfakol Raman Spektroskopisi incelemeleri}

Raman yöntemi, incelenen örnek üzerinde nokta analizi yaparak, örneğin mineralojik bileşiminin saptanmasını sağlamaktadır. Bu özelliği ile ince kesitte tespit edilen mineral parajenezi Raman spektumları ile de desteklenmiştir. Şekil 4c Konfakol Raman Spektroskopisinde mavi renk referans örneğe kırmızı renk ise analiz edilen üleksit örneğine ait pik değerlerini göstermektedir. Raman yöntemi ile kolemanit, hidroborasit ve üleksit varlı̆̆ı ortaya konmuştur.

\section{X-ışını difraktometresi (XRD) incelemeleri}

XRD yöntemi ise Raman ve mikroskop incelemelerinde tespit edilemeyen minerallerin tam olarak saptanması ve kil türlerinin belirlenmesinde kullanılmıştır. Emet Şeyhler boratlarına ait XRD incelemeleri örneklerde bor minerali olarak kolemanit (Şekil 3c), üleksit ve hidroborasitin (Şekil 3c) varlığını ortaya koymuştur. Bunların yanında XRD ile dolomit, kalsit, kristobalit, skolezit ile montmorillonit ve illite de rastlanmıştır. 
Sonuç olarak çalışmada Kolemanit $(\mathrm{Ca} \mathrm{B} \mathrm{O} .5 \mathrm{H} \mathrm{O})$, üleksit( $\mathrm{NaCa}[\mathrm{B} \mathrm{O}(\mathrm{OH})] \cdot 5 \mathrm{H} \mathrm{O})$ ve hidroborasit $\left(\mathrm{CaMgB} \mathrm{O} .6 \mathrm{H}^{5} \mathrm{O}^{6}\right)$ mineralleri tespit edilmiştir. Bor ${ }^{6}{ }^{11}$ mineralleri dişında dolomit, kalsit, kristobalit, skolezit, kil minerali olarak smektit grubu (montmorillonit) ve illite rastlanmıştır.

Önceki çalışmalarda Emet havzasındaki (Espey, Hisarc1k ve İğdeköy-Doğanlar) borat yataklarında yapılan incelemelerde; yerel oluşumlar şeklinde üleksit, tünellit, terrujit, kahnit, meyerhofferit, probertit ve viçit-A gibi borat mineralleri de belirlenmiştir (Helvacı ve Firman, 1977; Yalçın, 1984; Yalçın vd. 1985; Yalçın ve Gündoğdu, 1985; Yalçın ve Gündoğdu, 1987; Helvacı ve Orti, 1998; Helvac1, 1984; Çolak vd. 2000; Özkul, 2008). Kalsit, jips, nabit kükürt, realgar, orpiment, feldispat, kuvars, globerit, mika, opal-CT, anhidrit ve halit diğer minör-eser minerallerdir (Helvacı, 2003; Hatipoğlu, 2010).

\section{Emet Şeyhler Yatağının Jeokimyasal Özellikleri}

Emet Şeyhler yatağından alınan 18 adet borat (karot) örneğinde yapılan jeokimyasal analiz sonucunda element bollukları belirlenmiş ve korelasyonları hesaplanmıştır. Buna göre aşağıdaki bölümlerde açıklanan jeokimyasal değerlendirmelerde bulunulmuştur.

\section{Emet Şeyhler borat yatağının ana element bollukları}

Ana element sonuçları, ortalama değerleri ile yerkabuğunda (YKO), andezitlerde (AO) ve tatlı sularda (TSO) bulunan ortalama değerleri Çizelge 1'de verilmektedir. İS örneklerinde ana elementlerden Ca; YKO'ya göre 3.67 kat, B; 45792 kat, AO'ya göre ise Ca; 3.24 kat, B; 30528 kat artmıştır. Diğer tüm ana elementler ise hem YKO'ya hem de AO'ya göre azalma göstermektedir. Sirasiyla YKO'ya ve AO'ya göre verilen $\mathrm{Si}(20.63-22.80), \mathrm{Na}(3.02-3.78), \mathrm{Al}(20.87-$ 17.71), Fe (16.35-17.71), $\mathrm{Mg}(1.37-1.30), \mathrm{K}$ (9.47-10.37), Ti (24.41-39.06), P (9.69-14.10)'un değerlerinin azalma katsayıları görülmektedir.

Çizelge 1. Emet Şeyhler örneklerine ait ana element içerikleri (1) Krauskopf (1989), (2) Schroll (1975), (3) Abollino vd. (2004). * değer yok.

Table 1. Major element contents of Emet Şeyhler borate samples (1) Krauskopf (1989), (2) Schroll (1975), (3) Abollino et al. (2004). * no value.

\begin{tabular}{|c|c|c|c|c|c|c|c|c|c|c|c|c|c|}
\hline Örnek No & B2O3 (\%) & Si $(\%)$ & $\mathrm{Al}(\%)$ & $\mathrm{Fe}(\%)$ & $\operatorname{Mg}(\%)$ & $\mathrm{Ca}(\%)$ & $\mathrm{Na}(\%)$ & $\mathbf{K}(\%)$ & Ti(\%) & $\mathbf{P}(\%)$ & TOT/C(\%) & TOT/S(\%) & Sum(\%) \\
\hline IS-2 & 45.55 & 0.64 & 0.22 & 0.12 & 0.19 & 17.27 & 0.02 & 0.09 & 0.01 & 0.004 & 0.05 & 0.05 & 64.20 \\
\hline IS-3 & 49.19 & 0.93 & 0.16 & 0.21 & 1.81 & 12.94 & 2.10 & 0.06 & 0.01 & $<0.004$ & 0.30 & 0.54 & 68.24 \\
\hline IS-5 & 54.84 & 0.15 & 0.03 & 0.07 & 3.10 & 10.03 & 2.83 & 0.02 & $<0.006$ & $<0.004$ & 0.10 & 0.05 & 71.22 \\
\hline IS-7 & 41.47 & 0.28 & 0.05 & 0.04 & 0.77 & 17.72 & 0.62 & 0.01 & $<0.006$ & $<0.004$ & 0.54 & 0.02 & 61.53 \\
\hline IS-8 & 51.76 & 0.37 & 0.13 & 0.19 & 3.80 & 10.22 & 0.73 & 0.06 & $<0.006$ & $<0.004$ & 0.09 & 0.11 & 67.47 \\
\hline IS-9 & 44.87 & 0.21 & 0.08 & 0.11 & 0.07 & 19.80 & $<0.007$ & 0.04 & $<0.006$ & $<0.004$ & 0.04 & 0.05 & 65.28 \\
\hline IS-10 & 53.46 & 0.14 & 0.05 & 0.04 & 0.07 & 10.23 & 5.62 & 0.02 & $<0.006$ & $<0.004$ & $<0.02$ & $<0.02$ & 69.64 \\
\hline IS-11 & 44.41 & 1.28 & 0.45 & 0.64 & 0.30 & 16.95 & 0.07 & 0.22 & 0.02 & 0.009 & 0.06 & 0.28 & 64.68 \\
\hline IS-12 & 44.9 & 0.50 & 0.15 & 0.23 & 0.84 & 18.32 & 0.04 & 0.06 & 0.01 & $<0.004$ & 0.44 & 0.13 & 65.61 \\
\hline IS-13 & 51.15 & 0.73 & 0.24 & 0.85 & 4.28 & 12.67 & 0.04 & 0.12 & 0.01 & 0.013 & 0.14 & 0.47 & 70.71 \\
\hline IS-14 & 54.08 & 0.41 & 0.14 & 0.24 & 5.09 & 11.09 & 0.02 & 0.06 & $<0.006$ & $<0.004$ & 0.12 & 0.09 & 71.34 \\
\hline IS-15 & 45.45 & 1.59 & 0.43 & 0.26 & 0.78 & 17.25 & 0.05 & 0.27 & 0.02 & 0.004 & 0.10 & 0.05 & 66.25 \\
\hline IS-16 & 36.95 & 2.16 & 0.62 & 0.26 & 0.90 & 17.98 & 0.08 & 0.33 & 0.02 & 0.017 & 0.58 & 0.11 & 60.02 \\
\hline IS-17 & 43.67 & 3.62 & 0.93 & 0.49 & 4.21 & 11.09 & 0.12 & 0.57 & 0.04 & 0.009 & 0.32 & 0.71 & 65.78 \\
\hline IS-18 & 36.77 & 5.57 & 1.41 & 0.69 & 2.88 & 14.25 & 0.20 & 0.77 & 0.05 & 0.022 & 0.49 & 0.70 & 63.80 \\
\hline IS-19 & 43.91 & 1.39 & 0.52 & 0.60 & 0.23 & 18.89 & 0.04 & 0.29 & 0.02 & 0.009 & 0.05 & 0.27 & 66.21 \\
\hline IS-20 & 33.91 & 4.33 & 1.32 & 0.89 & 0.87 & 15.44 & 0.10 & 0.95 & 0.05 & 0.022 & 0.18 & 0.55 & 58.63 \\
\hline IS-21 & 47.92 & 0.32 & 0.05 & 0.03 & 0.10 & 18.88 & $<0.007$ & 0.05 & 0.01 & 0.004 & 0.06 & 0.15 & 67.56 \\
\hline Ortalama & 45.79 & 1.37 & 0.39 & 0.33 & 1.68 & 15.06 & 0.79 & 0.22 & 0.02 & 0.011 & 0.22 & 0.25 & 66.14 \\
\hline Değişim Aralığı & $33.91-54.84$ & $0.15-5.57$ & $0.03-1.41$ & $0.04-0.89$ & $0.03-5.09$ & $10.03-19.80$ & $<0.007-5.62$ & $0.01-0.95$ & $<0.006-0.05$ & $<0.004-0.022$ & $<0.02-0.54$ & $<0.02-0.71$ & $47.69-63.58$ \\
\hline Yerkabuğu Ort. (1) & 0.0010 & 28.20 & 8.10 & 5.40 & 2.30 & 4.10 & 2.40 & 2.10 & 0.5 & 0.11 & $*$ & $*$ & $*$ \\
\hline Andezit Ort. (2) & 0.0015 & 26.00 & 8.85 & 5.85 & 2.18 & 4.65 & 3.00 & 2.30 & 0.8 & 0.16 & $*$ & $*$ & * \\
\hline Tatlıs u Ort. (3) & 0.01 & 5.33 & $<30.10^{-3}$ & $<30.10^{-3}$ & $0.8-15.07 ; 3.64$ & $1.8-49.29 ; 13.22$ & $1.15-36.78 ; 5.28$ & $0.51-3.9 ; 12.9$ & $<1.10^{-3}$ & * & * & * & * \\
\hline
\end{tabular}




\section{Emet Şeyhler Borat Yatağının Eser Element Bollukları}

Emet Şeyhler ocağına ait eser element ortalama değerleri ile yerkabuğunda (YKO), andezitlerde (AO) ve tatlı sularda (TSO) bulunan ortalama değerleri Çizelge 2'de verilmektedir. Emet Şeyhler yatağındaki örneklerin tamamının eser element içerikleri TSO’ya göre belirgin bir artış göstermektedir (Çizelge 2). Emet Şeyhler yatağında YKO'ya ve AO'ya göre kıyaslama yapıldığında eser elementlerden, As, Se, Sr, Cs, $\mathrm{Sb}$ ve Li'nin diğer elementlere göre daha fazla artış gösterdiği görülmektedir. Sirası ile YKO’ya, ve AO'ya göre artış katsayıları As 1367-1295, Se 329-329, Cs 24.30-31.70, Sr 16.64-7.80, Sb 8.27-8.27, Li 2.86-2.86, kat şeklindedir. Ayrıca S ise 9.74-14.62 kat artmıştır.

Bigadiç yatağında; Se, Sr, As, Sb, Mo ve Li (Koçak ve Koç, 2012), Kestelek yatağında; Se, Sr, As, Sb, Cs, Li ve Mo (Koç vd., 2017), Kırka yatağında $\mathrm{Se}, \mathrm{Cs}$, Sr, Li ve As (Koçak ve Koç 2016), Emet (Espey-Hisarc1k) borat yatağında; $\mathrm{As}, \mathrm{Se}, \mathrm{Cs}, \mathrm{Li}, \mathrm{Sr}, \mathrm{Sb}$ ve $\mathrm{Pb}$ (Koçak, 2014) zenginleşmeleri belirlenmiştir. $\mathrm{Bu}$ veriler Kırka, Bigadiç, Emet (Espey-Hisarcık), Kestelek ve Emet Şeyhler yataklarında Se, Sr, Li ve As zenginleşmelerinin benzer bir özellik sunduğunu göstermektedir.
Nitekim Özkul vd. (2017)'nin Emet'te yaptığı çalışmada toprak anomalileri veren $\mathrm{Na}, \mathrm{Sr}, \mathrm{As}$ $\mathrm{Sb}$, Cs, As $\mathrm{K}$, Li, ve Be elementlerinin borat yataklarının bulunmasinda iz bulucu element olarak kullanılabileceğini belirtmiştir.

Bilindiği gibi pek çok maden yatağında ana cevhere ek olarak yan ürün halinde bazı elementler kazanılabilmektedir. Örneğin $\mathrm{Cu}$ yataklarında Se yan ürün olarak kazanılmaktadır. Çoğu bakır cevheri flotasyon konsantreleri 100-400 ppm Se içermekte ve dolayısıyla Se eldesi için en önemli kaynaklarından biridir (Habashi, 1997). Li için de benzer açıklamalaryapılabilir. Li üretimi birçok tuz yatağı, göl ve denizden sağlanmaktadır. Örneğin Li konsantrasyonları Salar de Uyuni (Bolivya)'da 240 ppm, Great Salt Lake (Utah) 40 ppm ve Ölü Deniz (İsrail-Ürdün) 20 ppm'dir (Habashi, 1997). Ayrıca deniz sularındaki 0.17 ppm'lik Li'un dahi elde edilmesi üzerine çalışılmaktadır (Habashi, 1997). Bor yataklarını değerlendirirken öncelikle Se (4-41 ppm) ve Li (34-324 ppm)'unda kazandırılabileceği düşünülmelidir. Bunun için Ar-Ge çalışmalarına ihtiyaç duyulmaktadır. Zenginleşen diğer elementler de bu kapsamda ele alınabilir. $\mathrm{Bu}$ çalışmada da zenginleştiği belirlenen As, Se, Sr, Cs, Sb ve Li gibi elementlerin yan ürün olarak kazanılması önerilmektedir. Böylece dünyada en çok Türkiye'de bulunan bor rezervlerinin daha ekonomik değerlendirmesi yapılmış olacaktır.

Çizelge 2. Emet Şeyhler örneklerine ait eser element içerikleri (1) Krauskopf (1989), (2) Schroll (1975), (3) Abollino vd. (2004), (4) Şahinci (1991).* değer yok.

Table 2. Trace element contents of Emet Şeyhler borate samples (1) Krauskopf (1989), (2) Schroll (1975), (3) Abollino et al. (2004), (4) Şahinci (1991). * no value.

\begin{tabular}{|c|c|c|c|c|c|c|c|c|c|c|c|c|c|c|c|c|c|c|c|c|c|}
\hline Örnek No & Se & $\mathbf{L i}$ & As & $\mathrm{Cs}$ & $\mathbf{s r}$ & Sb & Ba & Co & Nb & $\mathbf{R b}$ & Th & $\mathbf{U}$ & $\mathbf{Z r}$ & $\mathbf{Y}$ & Mo & $\mathrm{Cu}$ & $\mathbf{P b}$ & $\mathbf{N i}$ & Ag & Te(ppm) & $\mathrm{S}(\%)$ \\
\hline IS-2 & 30.1 & 14.1 & 61.4 & 34.8 & 6213.2 & 0.18 & 11 & 0.8 & 0.3 & 16.7 & 0.4 & 0.1 & 3.1 & 20 & $<0.01$ & 1.9 & 2.1 & 2.4 & 3 & 0.12 & $<0.02$ \\
\hline IS- -3 & 14.4 & 54.4 & $<10000$ & 29.2 & 3990.4 & 4.91 & 125 & 3.6 & 0.1 & 9.2 & 0.5 & 0.4 & 3.3 & 0.3 & 4.15 & 1.7 & 1.6 & 5.3 & 9 & 0.10 & 0.51 \\
\hline IS-5 & 8.6 & 11.8 & 744.5 & 7.8 & 3227.1 & 0.41 & 13 & $<0.2$ & $<0.1$ & 3.3 & $<0.2$ & $<0.1$ & 0.6 & 0.4 & 0.06 & 0.5 & 0.3 & 1.1 & 2 & 0.05 & $<0.02$ \\
\hline IS-7 & 23.6 & 16.9 & 709.4 & 31.9 & 7830.5 & 0.44 & 16 & $<0.2$ & $<0.1$ & 4.6 & $<0.2$ & 0.7 & 1.4 & 0.4 & 0.03 & 0.5 & 0.8 & 3.2 & 2 & 0.12 & $<0.02$ \\
\hline IS-8 & 10.9 & 11.8 & 1918.1 & 24.7 & 33104.4 & 1.73 & 65 & 0.3 & $<0.1$ & 10.4 & $<0.2$ & 0.4 & 1.8 & 1.6 & 0.11 & 1.2 & 1.4 & 3.9 & 5 & 0.52 & 0.12 \\
\hline IS-9 & 28.8 & 7.3 & 74.3 & 211.0 & 4137.8 & 0.24 & 6 & 0.6 & $<0.1$ & 7.1 & $<0.2$ & 0.1 & 1.2 & 1.1 & 0.09 & 0.3 & 0.7 & 5.2 & $<2$ & 0.10 & 0.02 \\
\hline IS-10 & 7.6 & 5.3 & 406.7 & 9.9 & 1472.6 & 0.19 & 21 & $<.2$ & $<0.1$ & 3.7 & $<0.2$ & $<0.1$ & 1.1 & 1.5 & 0.02 & 0.3 & 0.2 & 2.3 & $<2$ & 0.03 & $<0.02$ \\
\hline IS-11 & 19.9 & 35.1 & 137.4 & 86.1 & 6085.3 & 4.31 & 27 & 5.0 & 0.6 & 33.6 & 1.1 & 0.5 & 6.0 & 4.1 & 0.12 & 6.9 & 2.4 & 32.5 & 103 & 0.12 & 0.25 \\
\hline IS-12 & 18.6 & 22.5 & 2467.7 & 24.9 & 4439.7 & 1.56 & 93 & 0.8 & 0.3 & 8.8 & 0.5 & 0.3 & 2.4 & 2.3 & 0.05 & 2.5 & 2.4 & 9.1 & 11 & 0.27 & 0.09 \\
\hline IS-13 & 10.8 & 33.0 & 848.4 & 50.4 & 3848.7 & 6.37 & 147 & 22 & 0.3 & 20.7 & 0.4 & $<0.1$ & 3.3 & 19 & 0 & 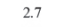 & 2 & 24.4 & & 0 & 0.48 \\
\hline IS-14 & 10.8 & 17.0 & 1957.8 & 23.4 & 939.4 & 0.64 & 29 & 0.6 & $<0.1$ & 10.1 & 0.3 & $<0.1$ & 1.8 & 1.5 & 0.05 & 1.0 & 1.5 & 5.8 & 22 & 0.09 & 0.06 \\
\hline IS-15 & 19.9 & 75.2 & 241.8 & 66.0 & 4566.6 & 0.54 & 35 & 2.3 & 0.6 & 32.4 & 1.1 & 0.9 & 5.6 & 4.2 & $<0.01$ & 2.2 & 3.0 & 17.2 & 48 & 0.14 & $<0.02$ \\
\hline IS-16 & 20.1 & 109.6 & 2675.0 & 60.1 & 4572.0 & 1.01 & 213 & 22 & 1.1 & 43.0 & 1.1 & 1.1 & 8. & 2.7 & 0.07 & & 3.5 & 10. & 3 & 0. & 0.09 \\
\hline IS-17 & 11.5 & 185.8 & $<10000$ & 147.1 & 2907.3 & 1.73 & 171 & 3.4 & 1.5 & 60.4 & 2.0 & 0.7 & 11.7 & 5.3 & 3.40 & 3.6 & 4.3 & 37.0 & 21 & 0.13 & 0.69 \\
\hline IS-18 & 9.7 & 269.1 & $<10000$ & 222.7 & 4216.2 & 1.37 & 181 & 4.4 & 2.4 & 92.3 & 3.1 & 1.9 & 18.5 & 5.1 & 3.41 & 5.0 & 4.6 & 54.3 & 42 & 0.07 & 0.61 \\
\hline IS-19 & 20.9 & 23.0 & 173.9 & 98.9 & 5524.3 & 2.06 & 19 & 4.4 & 0.5 & 47.1 & 0.9 & 0.2 & 5.2 & 5.1 & 0.41 & 1. & 1.5 & 121.8 & 3 & 0 & 0.24 \\
\hline IS-20 & 9.8 & 120.2 & 1642.1 & 182.0 & 10970.0 & 1.91 & 264 & 3.1 & 2.6 & 115.0 & 3.3 & 1.8 & 20.8 & 3.7 & 0.28 & 7.3 & 5.2 & 21.7 & 16 & 0.28 & 0.53 \\
\hline IS-21 & 20.4 & 16.0 & 256.6 & 1.3 & 4284.8 & 0.17 & 87 & 1.4 & $<0.1$ & 3.5 & 0.5 & 0.7 & 1.9 & 3.1 & $<0.01$ & 0.2 & 0.6 & 0.4 & 3 & 0.16 & 0.11 \\
\hline Ortalama & 16.5 & 57.1 & 954.3 & 72.9 & 6240.6 & 1.7 & 84.6 & 2.3 & 0.9 & 29.0 & 1.2 & 0.7 & 5.4 & 2.6 & 0.8 & 2.3 & 2.2 & 19.9 & 21.7 & 0.1 & 0.3 \\
\hline Degişim Aralığ & $7.6-30.1$ & $5.3-269.1$ & $61.4-<10000$ & $1.3-222.7$ & $939.4-33104.4$ & $0.17-6.37$ & $6-264$ & $<0.2-5.0$ & $<0.1-2.6$ & $3.3-115.1$ & $<0.2-3.3$ & $<0.1-1.9$ & $0.6-20.8$ & $0.3-5.3$ & $<0.01-4.15$ & $0.5-7.3$ & $0.2-5.2$ & $1.1-121.8$ & $3-121$ & $0.05-0.52$ & $<0.02-0.69$ \\
\hline erkabuğu Ort. (1) & 0.05 & 20 & 1.8 & 3 & 375 & 0.2 & 500 & 22 & 20 & 90 & 8.5 & 2.7 & 165 & 35 & 1.5 & 50 & 12.5 & 75 & 70 & * & 0.03 \\
\hline Andezit Ort. (2) & 0.05 & 20 & 1.9 & 2.3 & 800 & 0.2 & 714 & 10 & 20 & 72 & 7 & 1.8 & 260 & 25 & 0.9 & 35 & 15 & 55 & 70 & * & 0.02 \\
\hline Tathsu Ort. (3) & $0.1 .10-3$ & $1.10-3$ & $2.10-3$ & $1.8 .10-3(4)$ & $50.10-3$ & $0.1 .10^{-3}$ & $10.10-3$ & $0.05 \cdot 10-3$ & $*$ & * & * & $0.05 .10-3$ & 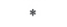 & $*$ & $1.10-3$ & $1.8 .10-3$ & $0.2 \cdot 10-3$ & $0.3 \cdot 10-3$ & $0.3 .10^{6}$ & * & $*$ \\
\hline
\end{tabular}




\section{Emet Şeyhler Yatağının Ana ve Eser Element Korelasyonları}

Şeyhler boratlarına ait kümeleme analizi esas olarak 2 ana grup element varlığını göstermektedir. Birinci grup; Zr, Nb, K, Rb, Th, Ti, Al, Si, NTE, $\mathrm{Pb}, \mathrm{P}, \mathrm{Li}, \mathrm{U}, \mathrm{Cs}, \mathrm{Cu}, \mathrm{Ba}, \mathrm{Fe}, \mathrm{Y}, \mathrm{TOT} / \mathrm{S}, \mathrm{Co}, \mathrm{Ni}, \mathrm{Mo}$, $\mathrm{As}, \mathrm{Ag}, \mathrm{TOT} / \mathrm{C}, \mathrm{Mg}$ ve $\mathrm{Sb}$, ikinci grup ise $\mathrm{Te}, \mathrm{Sr}$, $\mathrm{Se}, \mathrm{Ca}, \mathrm{Na}$ ve $\mathrm{B}_{2} \mathrm{O}_{3}$ elementlerinden oluşmaktadır (Şekil 5). İkinci grupta yer alan elementlerin ikili benzerlikleri yüksek iken (Te-Sr gibi) birbirleri ile arasındaki benzerlik oldukça düşüktür (Te-Sr ile Ca-Se gibi).
Si, Al, Fe, K ve Ti gibi elementler hem kendi aralarında hem de birlikte grup oluşturdukları eser elementler ile birlikte kuvvetli-çok kuvvetli pozitif korelasyon katsayıları vermişlerdir. Te, $\mathrm{Sr}, \mathrm{Se}, \mathrm{Ca}$, $\mathrm{Na}$ ve $\mathrm{B}_{2} \mathrm{O}_{3}$ elementleri ise gruplaştı $\breve{g}_{1}$ elementlerle düşük pozitif korelasyon göstermektedir. Ancak $\mathrm{Na}-\mathrm{B}_{2} \mathrm{O}_{3}(\mathrm{r}=0.49)$ hariç ikili çiftler arasında korelasyon katsayıları (Örn Ca-Se 0.84) yüksektir (Çizelge 3). Ca'un $\mathrm{Si}, \mathrm{Al}, \mathrm{Fe}, \mathrm{K}$ ve Ti grubu elementlerle genel olarak gözlenen negatif ilişkisi ise bunların kökensel olarak farklı olduğunu işaret etmektedir.

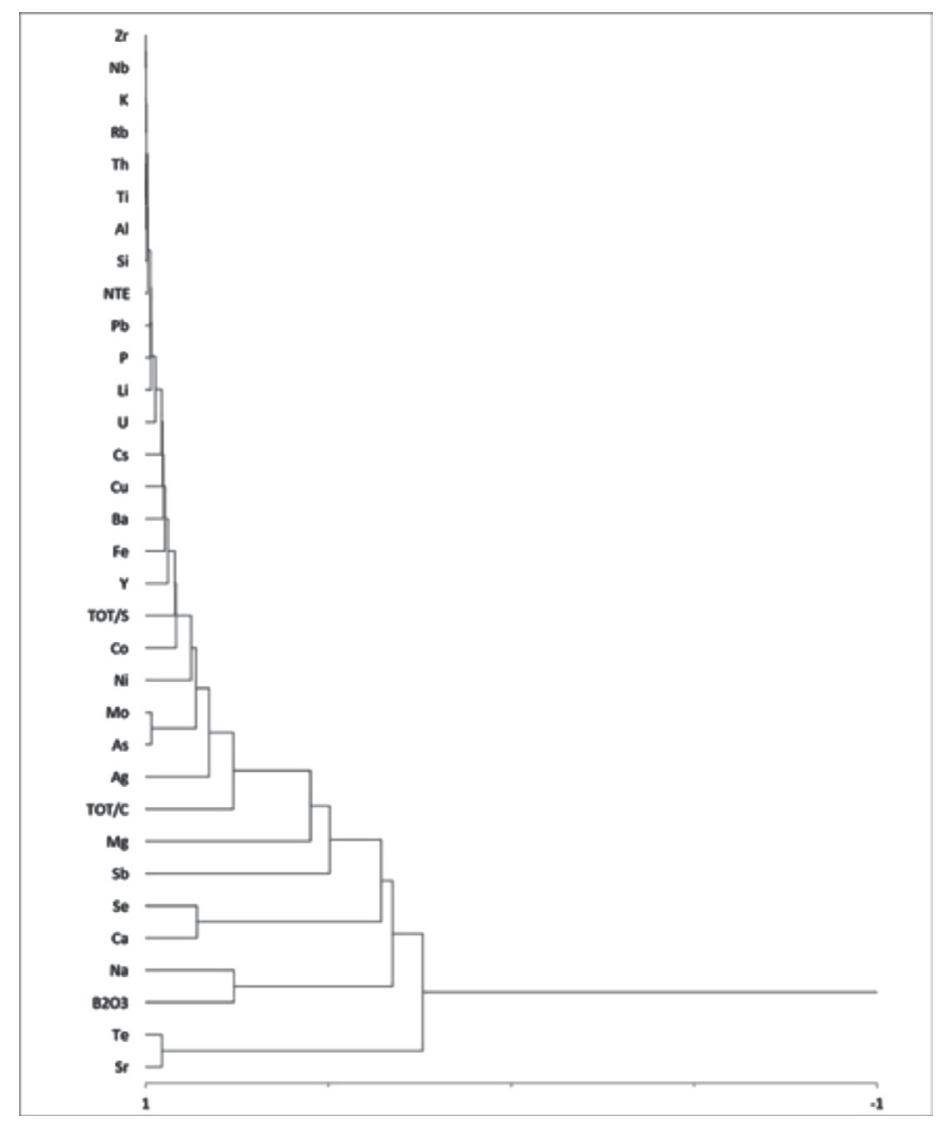

Şekil 5. Emet Şeyhler Bölgesi borat örneklerine ait kümeleme dendogramı

Figure 5. Cluster dendrogram for elements of Emet Şeyhler region borate samples. 
Çizelge 3. Emet Şeyhler Bölgesine ait borat örneklerinin korelasyon katsayıları

Table 3. Correlation coefficients for the Emet Şeyhler borate samples.

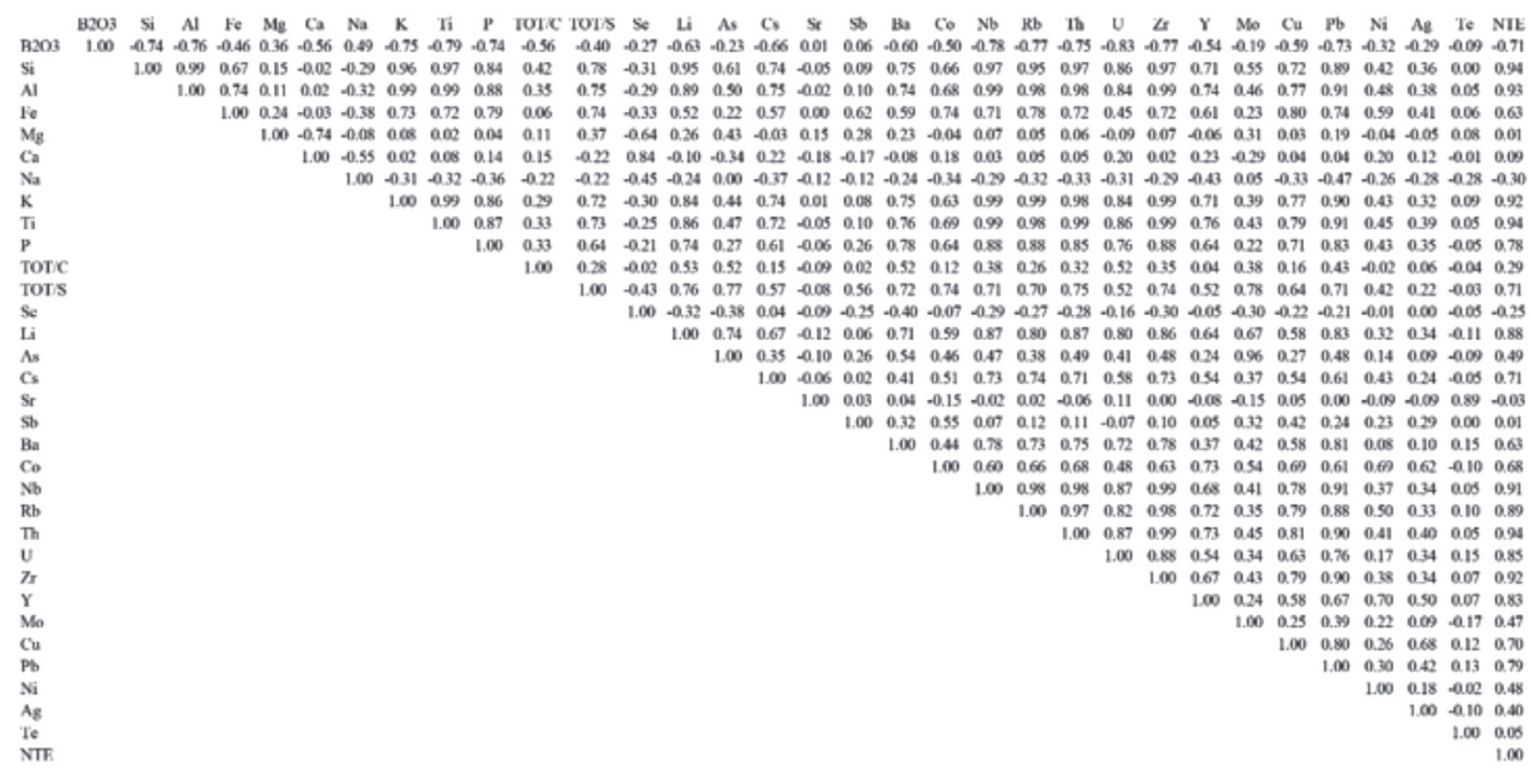

Şeyhler yatağı örneklerinin element kümelenmelerine baktığımızda genellikle kil grubu elementlerin ( $\mathrm{Si}, \mathrm{Al}, \mathrm{Fe}, \mathrm{K})$ büyük bir grup şeklinde hareket ettiği görülmektedir. Bor minerali içerisinde zenginleştiği görülen eser elementlerden As, Cs, Sb ve Li'un kil grubu elementlerle, Se'un $\mathrm{Ca}$ ile pozitif, Sr'un ise Te ile pozitif korelasyonu söz konusudur (Çizelge 3). $\mathrm{B}_{2} \mathrm{O}_{3}$ 'un Na ile 0.49 ilişkisi dışında diğer hiçbir elementle pozitif anlamda önemli bir ilişkisi yoktur. $\mathrm{Bu}$ durum $\mathrm{B}_{2} \mathrm{O}_{3}$ 'un kökensel olarak büyük gruptan farklı bir kaynaktan geldiğini göstermektedir (Çizelge 3).

Birlikte hareket ettikleri belirlenen büyük gruba ait $\mathrm{Si}, \mathrm{Al}$ ve Ti gibi ana elementler, $\mathrm{Cr}, \mathrm{Zr}$ gibi eser elementler ve NTE alterasyona karşı çok duraylı olup, detritik kökeni işaret ederler (Boggs, 2009; Fu vd. 2011). Buna göre bu grubu oluşturan elementler karasal katkıyı gösteren killerle birlikte göl ortamına taşınmışlardır.

Şeyhler bölgesine ait element davranışları genel olarak birbirine benzemektedir. Başta $\mathrm{Si}$ ve Al olmak üzere Fe, K, Na gibi ana elementler genel olarak karasal kökeni (detritik) ve killere bağlı hareketi (taşınma ve çökelmeyi) işaret eder. $\mathrm{Bu}$ elementlerin birlikte hareket ettiği eser elementler için de aynı açıklama söz konusudur.

\section{Nadir Toprak Element Analizi (NTE)}

Şeyhler yatağının oluşum ortamına ait bazı fizikokimyasal şartları belirlemek için boratların NTE içeriklerinden yararlanılmıştır. Bunun için NTE analiz sonuçları PAAS ortalamalarına göre normalize edilmiş (Taylor ve McLennan,1985) ve örümcek diyagramları çizilmiştir (Çizelge 4; Şekil 6).

Emet Şeyhler örneklerinin $\sum$ NTE ortalamas1 0.73-32.22 ppm arasında ve ortalama $10.81 \mathrm{ppm}$ değerindedir (Çizelge 4). Bu değerler, NTE'nin Şeyhler bölgesinde oldukça düşük değerlerde olduğunu göstermektedir. Ayrıca, Hafif Nadir Toprak Elementlerin (HNTE) bollukları, Ağır Nadir Toprak Elementlere (ANTE) göre daha fazladır.

Çalışma alanındaki örneklerde belirgin $\mathrm{Ce}$ ve $\mathrm{Eu}$ anomalileri görülmektedir (Şekil 6). $\mathrm{Bu}$ anomaliler $\mathrm{Ce}^{*}=\mathrm{CeN} . /\left[2 / 3 \mathrm{~L}_{\text {anorm. }}+1 / 3 \mathrm{Pr}_{\text {norm. }}\right]$, 
$\mathrm{Eu}^{*}=\mathrm{Eu}_{\mathrm{N}} /\left[2 / 3 \mathrm{Sm}_{\mathrm{N}}+1 / 3 \mathrm{Gd}_{\mathrm{N}}\right]$ ve Ceanom $=\log$ [3 $\times$ CeN / ( $2 \times \mathrm{LaN}+\mathrm{NdN})]$ formülleri ile hesaplanmıştır. Buna göre Şeyhler bölgesi örneklerinde hesaplanan $\mathrm{Ce}^{*}$ değeri ortalama 0.93 (0.79-1.36), Eu* değerleri ortalama 1.26 (0.78-1.93) iken $\mathrm{Ce}_{\text {anom }}$ değeri ortalama -0.05 $(-0.15$ ile 0.07$)$ 'dir.
$\mathrm{Ce}_{\text {anom }}>-0.1$ değeri Ce'un zenginleşmesini, $\mathrm{Ce}_{\text {anom }}<-0.1$ durumu ise negatif $\mathrm{Ce}$ anomalisini işaret eder (Wright ve Holser, 1987). Şeyhler boratlarında $\mathrm{Ce}_{\text {anom }}<-0.1$ olması (Çizelge 4) ortamın oksijenli olduğunun göstergesidir (Constantopoulos, 1988; Canet vd. 2005). Ayrica Fleet vd. (1976) tarafindan hafif negatif $\mathrm{Ce}$ anomalisinin volkanik girdiyi işaret ettiği bildirilmiştir (Şaşmaz vd. 2014).

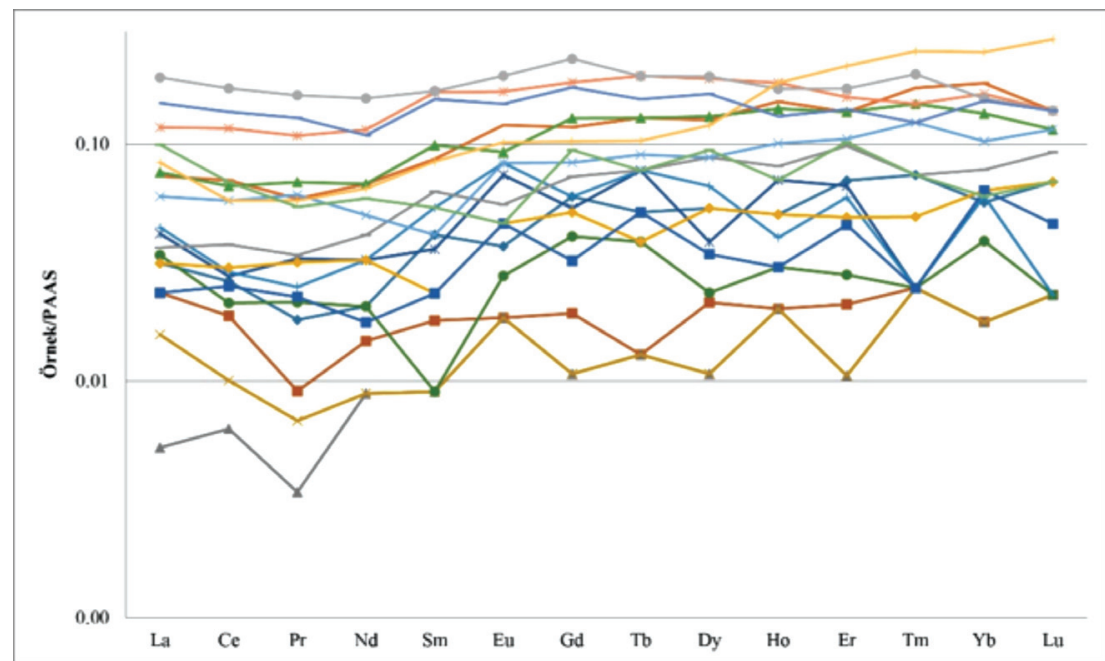

Şekil 6. Şeyhler borat örnekleri NTE dağılımları (Taylor ve McLennan, 1985'e göre normalize edilmiştir)

Figure 6. REE distribution for Şeyhler borate samples (normalized with Taylor and McLennan 1985

Çizelge 4. Emet Şeyhler borat örneklerine ait Nadir Toprak Element jeokimyası sonuçları (1) Krauskopf (1989),(2) Schroll (1975), (3) Abollino et al. (2004)* değer yok.

Table 4. Rare earth elements contents of Emet Seyhler borate samples. (Continued) (1) Krauskopf (1989), (2) Schroll (1975), (3) Abollino et al. (2004).(1991). * no value.

\begin{tabular}{|c|c|c|c|c|c|c|c|c|c|c|c|c|c|c|c|}
\hline Ōrnck No & $\mathbf{L a}$ & $\mathrm{Ce}$ & $\mathrm{Pr}$ & Nd & $S m$ & Eu & Gd & $\mathbf{T b}$ & Dy & Н & Er & $\mathbf{T m}$ & $\mathbf{Y b}$ & La & $\mathbf{Y}$ \\
\hline IS-2 & 1.20 & 2.10 & 0.16 & 0.70 & 0.23 & 0.04 & 0.28 & 0.04 & 023 & 0.05 & 0.20 & 0.03 & 0.16 & 0.03 & 200 \\
\hline IS-3 & 0.90 & 1.50 & 0.08 & 0.50 & 0.10 & $\infty .02$ & 0.09 & 40.01 & 0.10 & $\infty 0.02$ & 0.06 & $<0.01$ & 40.05 & $<0.1$ & 0.30 \\
\hline IS-5 & 0.20 & 0.50 & 0.03 & 40.3 & $<0.05$ & 40.02 & $<0.05$ & 40.01 & 80.05 & 40.02 & 40.03 & 40.01 & 40.05 & $<0.01$ & 0.40 \\
\hline IS-7 & 0.60 & 0.80 & 0.06 & $<0.3$ & $<0.05$ & $<0.02$ & $<0.05$ & 40.01 & 40.05 & 40.02 & 40.03 & $<0.01$ & 40.05 & $<0.01$ & 0.40 \\
\hline IS-8 & 1.60 & 2.20 & 0.29 & 1.10 & 0.20 & 0.08 & 0.25 & 0.06 & 0.18 & 0.07 & 0.19 & 0.01 & 0.17 & $<001$ & 1.60 \\
\hline IS-9 & 1,30 & 1,70 & 0,19 & 0,70 & $<0,05$ & 0,03 & 0,19 & 0,03 & 0,11 & 0,03 & 0,08 & 40,01 & 0,11 & $\angle 0,01$ & 1,10 \\
\hline IS-10 & 1.70 & 2.30 & 0.22 & 1. 10 & 0.30 & 0.09 & 0.28 & 0.06 & 0.31 & 0.04 & 0.17 & 40.01 & 0.17 & 0.01 & 1.50 \\
\hline IS-11 & 2.80 & 5.60 & 0.52 & 2.30 & 0.48 & 0.13 & 0.55 & 0.10 & 0.59 & 0.15 & 0.39 & 0.07 & 0.51 & 0.06 & 4.10 \\
\hline IS-12 & 1.40 & 3.00 & 0.30 & 1.40 & 0.35 & 0.06 & 0.34 & 0.06 & 0.41 & 0.08 & 0.28 & 0.03 & 0.22 & 0.04 & 2.30 \\
\hline IS-13 & 1.20 & 2,40 & $0.2 \mathrm{x}$ & 1.10 & 0.13 & 0.05 & 0.24 & 0.03 & 0.25 & 0,05 & 0,14 & 0,02 & 0,18 & 0,03 & 1.90 \\
\hline IS-14 & 0.90 & 2.00 & 0.20 & 0.60 & 0.13 & 0.05 & 0.15 & 0.04 & 0.16 & 0.03 & 0.13 & 0.01 & 0.18 & 0.02 & 1.50 \\
\hline IS-15 & 2.90 & 5.30 & 0.61 & 2.30 & 0.55 & 0.10 & 0.60 & 0.10 & 0.61 & 0.14 & 0.39 & 0.06 & 0.38 & 0.05 & 4.20 \\
\hline IS-16 & 2.30 & 4.60 & 0.54 & 1.70 & 0.23 & 0.00 & 0.39 & 0.07 & 0.41 & 0.10 & 0.30 & 0.05 & 0.20 & 0.05 & 270 \\
\hline IS-17 & 4.50 & 9.30 & 0.96 & 3.90 & 0.92 & 0.18 & 0.85 & 0.15 & 0.88 & 0.18 & 0.45 & 0.06 & 0.46 & 0.06 & 5.30 \\
\hline IS-18 & 7.30 & 13.70 & 1.42 & 5.30 & 0.93 & 0.21 & 1.07 & 0.15 & 0.90 & 0.17 & 0.49 & 0.08 & 0.44 & 0.06 & 5.10 \\
\hline IS-19 & 3.20 & 4.60 & 0.51 & 2.20 & 0.47 & 0.11 & 0.48 & 0.08 & 0.56 & 0.18 & 0.61 & 0.10 & $0 . \omega$ & 0.12 & 5.10 \\
\hline IS-20 & 5.70 & 10.90 & 1.14 & 3.70 & 0.86 & 0.16 & 0.81 & 0.12 & 0.76 & 0.13 & 0.40 & 0.05 & 0.43 & 0.06 & 3.70 \\
\hline IS-2I & 3.80 & 5.50 & 0.48 & 2.00 & 0.30 & 0.05 & 0.44 & 0.06 & 0.44 & 0.07 & 0.29 & 0.03 & 0.17 & 0.03 & 3.10 \\
\hline Ortakama & 2.42 & 4.33 & 0.44 & 1.91 & 0.41 & 0.10 & 0.44 & $0.0 \mathrm{~K}$ & 0.43 & 0.10 & 0.29 & 0.05 & 0.30 & 0.05 & 2.57 \\
\hline De p̣igim Aralığı & $0.20-7.30$ & $0.50-13.70$ & $0.03-1.42$ & $<0.35 .30$ & $<.05-0.93$ & $<0.02-0.21$ & $<0.05-1.07$ & $40.01-0.15$ & $<0.05-0.90$ & $<0.02-0.18$ & $-0.03-0.61$ & $<0.0-10.10$ & $<0.05-0.69$ & $40.01-0.12$ & $0.30-5.30$ \\
\hline Yerkabuḡu Ort. (1) & 35 & 70 & 8 & 30 & 7 & 1.2 & 7 & 1 & 6 & 1.5 & 3.5 & 0.5 & 3.5 & 0.6 & 35 \\
\hline Ande nit Ort. (2) & $\cdot$ & • & $*$ & - & ? & $?$ & - & * & - & + & + & + & - & * & 25 \\
\hline Tatlisu Ont. (3) & - & - & • & - & - & - & - & - & - & - & - & * & - & - & $*$ \\
\hline
\end{tabular}


Çizelge 4/Table 4 (devam/ (Continued))

\begin{tabular}{|c|c|c|c|c|c|c|c|c|c|}
\hline Örnek No & HNTE & ANTE & TNTE & HNTE/ANTE & Cenanom= $\log |3 \times \operatorname{CeN} /(2 \times \operatorname{LaN}+\mathrm{NuN})|$ & $\mathrm{Ce}^{*}=\mathrm{CeN}_{\mathrm{N}} / 2 / 3 \mathrm{~L}$.anorm.+1/3Prmarm.| & Cexice" & $\left.\mathrm{Eu}^{*}-\mathrm{EuN} / 2 / 3 \mathrm{SmV}+1 / 3 \mathrm{GdN}\right]$ & УНо \\
\hline IS-2 & 4.43 & 1.04 & 5.47 & 4.26 & -0.02 & 0.98 & 0.03 & 0.78 & 40,00 \\
\hline $15-3$ & 308 & 0.25 & 3.33 & 12.32 & -0.04 & 1.01 & 002 & 1.00 & 15,00 \\
\hline 15-5 & a.73 & 000 & 0.73 & 0.00 & -0.01 & 1.36 & 000 & 1.93 & 20.00 \\
\hline 15-7 & 1.46 & 000 & 1.46 & 0.00 & -0.13 & 0.79 & 0.01 & 1.93 & 20.00 \\
\hline IS-8 & 5.47 & a93 & 6.20 & 5.88 & - a.1s & 0.71 & 004 & 1.77 & 22.86 \\
\hline Is-9 & 3.92 & 0.55 & 4.47 & 7.13 & -0.14 & 0.72 & 0.03 & 1.42 & 36.67 \\
\hline 1S.10 & 5.71 & 1.04 & 6.75 & 5.49 & .0 .15 & 0.76 & 004 & 1.49 & 37.50 \\
\hline 18-11 & 11.83 & 2.42 & 14.25 & 4.89 & -0.01 & 1.03 & 0.07 & 1.24 & 27.33 \\
\hline 1S-12 & 6.51 & 1.46 & 7.97 & 4.46 & .001 & 1.05 & 0.04 & 0.84 & 28.75 \\
\hline $15-13$ & 5.16 & 094 & 6.10 & 5.49 & -0.02 & 0.96 & 0.03 & 1.41 & 38.00 \\
\hline $15-14$ & 3.88 & a.72 & 4.60 & 5.59 & 0.07 & 1.08 & 002 & 1.76 & 50.00 \\
\hline $15-15$ & 11.76 & 233 & 14.09 & 5.05 & -0.04 & 0.90 & 0.07 & 0.85 & 30.00 \\
\hline $15-16$ & 9.46 & 1.66 & 11.12 & 5.70 & 0.01 & 0.95 & 006 & 1.50 & 27.00 \\
\hline $15-17$ & 19.76 & 309 & 22.85 & 6.39 & 0.00 & 1.02 & 0.11 & 0.97 & 29.44 \\
\hline $15-18$ & 28.86 & 3.36 & 32.22 & 8.99 & $-a, 02$ & 0.95 & 0.18 & 1.03 & 30.00 \\
\hline $15-19$ & 11.00 & 282 & 13.91 & 3.93 & -0.13 & 0.77 & 008 & 1.12 & 28.33 \\
\hline $15-20$ & 22.46 & 276 & 2522 & 8.14 & 0.00 & 0.96 & 0.14 & 0.92 & 28.46 \\
\hline $15-21$ & 12.13 & 1.53 & 13.66 & 7.93 & -009 & 0.82 & $a 0 s$ & 0.69 & 44.29 \\
\hline Ortalamm & 9.32 & 1.49 & 10.81 & 5.61 & -0.05 & 0.93 & 0.06 & 1.26 & 30.76 \\
\hline Değhis im Arralugt: & $0.73-28.86$ & $0.0-3.36$ & $0.73-3222$ & $00-12.32$ & - & - & - & - & • \\
\hline Yerkabugu Ort. (1) & - & - & - & - & - & - & - & - & • \\
\hline Ande zit Ont. (2) & - & - & - & - & - & - & * & - & • \\
\hline Tattsu Ort. (3) & - & - & - & - & - & - & - & - & • \\
\hline
\end{tabular}

Çizelge 4'e göre Şeyhler bölgesinde 12 seviyede pozitif $\mathrm{Eu}$ anomalisi 6 seviyede de negatif Eu anomali olduğu görülmektedir. Negatif $\mathrm{Eu}$ anomalisi farklı ortamlarda görülebildiğinden bölge de görülen negatif $\mathrm{Eu}$ anomalisine dayalı belirli bir yorum yapmak güçtür. Borun Şeyhler yatağında göl ortamı ve volkanik faaliyetlerle (hidrotermal çözeltilerle) ilişkisi göz önüne alındığında NTE'nin doğal ve hidrotermal sulardaki dağılımını da dikkate almak gerekir. Hidrotermal suları okyanusal ve kıtasal kökenli olarak siniflandiran McLennan (1989), kitasal kökenli hidrotermal suları da yüksek ve düşük pH'lı olmak üzere ikiye ayırmıştır. Ayrıca negatif $\mathrm{Eu}$ anomalisi gösteren sular bu yazar tarafindan kıtasal ortamın yüksek $\mathrm{pH}^{\prime} \mathrm{l}_{1}$ hidrotermal suları olarak tanımlanmıştır. Buna göre, negatif $\mathrm{Eu}$ anomalisi gösteren Şeyhler bölgesi çökelme ortamının yüksek pH'lı hidrotermal sular tarafından beslendiği ortaya çıkmaktadır. Diğer bir değerlendirmede, negatif $\mathrm{Eu}$ anomalisi, oksijeni az indirgen ortamları gösteren bir faktör olarak ileri sürülmektedir (Constantopoulos, 1988; Henderson, 1984). Hidrotermal çözeltiler ve yıkanma (leacing) olayları, Eu ${ }^{3+}$ ün' $\mathrm{Eu}^{2+}$ ye indirgenmesine ve dolayssiyla negatif $\mathrm{Eu}$ anomalisine sebep olmaktadır (Sverjensky, 1984; Bau, 1991; Bence ve Taylor, 1985).

Pozitif Eu anomalisinin magmatik kökenin işaretçisi olduğu gibi (Nonce ve Taylor, 1977;
Bhatia, 1985; Sant'Anna vd. 2005) aynı zamanda $\mathrm{CO}_{2}$ varlığını göstermektedir. (Graf, 1977, Gale vd. 1997) ve bu da ortamdaki volkanik faaliyetlerin ürettiği $\mathrm{CO}_{2}$ ile ilişkilendirilebilir.

$\mathrm{Bu}$ açıklamalara göre, Şeyhler bölgesinde görülen negatif $\mathrm{Eu}$ anomalisi, oksijenli göl ortamında oluşan borat oluşumları dikkate alındığında açıklanması gereken bir sorun haline gelmektedir. Çünkü oksijence zengin böyle ortamlarda $\mathrm{Eu}^{2+}$ kolaylikla $\mathrm{Eu}^{3+} \mathrm{e}$ yükseltgenerek $\mathrm{Ca}$ ve $\mathrm{Na}$ gibi elementlerle iyon yarıçapları yakınlığından dolayı borat oluşumuna katılabilir ve bu da pozitif Eu anomalisine sebep olabilir. O halde Şeyhler boratlarındaki negatif $\mathrm{Eu}$ anomalisinin başka bir açıklaması olmalıdır. Öncelikle hidrotermal sularla ve yan kayaç feldspatlarının kimyasal alterasyonuyla göl ortamına yeterince $\mathrm{Eu}$ taşınmadığı ileri sürülebilir. Pozitif Eu anomalisi köken açısından Ca-plajiyoklazları işaret etmektedir (Weill ve Drake,1973). İnceleme alanındaki volkanitlerin Ca-plajiyoklas içeriğinin bol ve alterasyonun yeterli etkinlikte olması durumunda Emet Şeyhler borat yatağını oluşturan göl ortamında Eu artışı olurdu. Kitasal kabuk katkısının yeterli olmamas1 yüzünden negatif Eu anomalisinin ortaya çıkması Usui ve Mita (1995) tarafindan iklimin soğuk oluşu ve alterasyonun az oluşuna bağlanmıştır (Şaşmaz vd. 2014). 
Ca-borat çökeliminin olduğu seviyelerde çok hafif de olsa pozitif Ho anomalisi belirlenmiştir. $\mathrm{Bu}$ durum Ho'un, Ca ile iyon yarıçapı benzerliğinden kaynaklanmaktır.

Şeyhler bölgesi boratlarında Y/Ho değerleri ortalaması 30 (15-44) olarak bulunmuştur. Modern deniz suyu, kondrite (26 -28) göre önemli derecede yüksek bir Y / Ho oranına (44-74) sahiptir (Kamber ve Webb, 2001). Jeolojik malzemelerin büyük çoğunluğu (tüm volkanik kayaçlar ve kırıntılı çökeller dahil) kondritik oranlara sahiptir (Nozaki vd. 1997). Şeyhler boratlarının da kondritik oranlara sahip oldukları görülmektedir.

HNTE bileşenleri, ANTE bileşenlerinden daha duraylıdir (Cantrell ve Bryne 1987). HNTE'lerindeki zenginleşme, hidrotermal sistemin herhangi bir yerinde NTE'lerin yıkanarak yeniden depolanması anlamını da taşır. ONTE zenginleşmesinin, sıcak doğal akışkanlar ve asit yıkanmalarında gözlenmesi karakteristiktir (Fee vd. 1992, Johannesson vd. 1996). Aynı zamanda orta asidik kaynaktan çıkan NTE bileşenleri, pozitif $\mathrm{Eu}$ anomalisi ve ONTE zenginleşmesi göstermektedir (Johannesson vd. 1996).

Sonuç olarak, Emet Şeyhler borat bölgesinde hesaplanan Ce değerleri ve anomalileri borat çökelim ortamının oksijenli bir ortam olduğunu göstermektedir.Ancak, incelenen bazı örneklerdeki düşük Ce anomalisi kısmi oksijenli ortamı işaret ettiğinden (Kato ve Isoxaki, 2009), boratları oluşturan göl ortamının bazı kesimlerinde $\mathrm{H}_{2} \mathrm{~S}$ 'li hidrotermal çözeltilerin katkısı olabileceği de düşünülmelidir. Nitekim Emet borat yataklarındaki realgar, orpiment ve nabit kükürt minerallerinin varlığ 1 , bu yorumu destekler niteliktedir. 6 örnekte belirlenen zayıf negatif Eu anomalisi ise, karalarda yeterli alterasyon gelişmemesi ve dolayısıyla göl ortamına yeterli Eu katkısının olamayışıyla açıklanabilir.

\section{SONUÇLAR}

Şeyhler yatağında bor minerali olarak kolemanit, üleksit ve hidroborasit mineralleri tespit edilmiştir. Bor mineralleri dışında dolomit, kalsit, kristobalit, skolezit, kil minerali olarak smektit grubu (montmorillonit) ve illite rastlanmıştır.

Emet yataklarında ana elementlerden $\mathrm{Ca}$, YKO'ya ve AO'ya göre artış göstermiştir. Eser elementlerden de As, Se, Cs, Sr, Sb ve Li zenginleşmeleri belirlenmiştir.

Özellikle borat yatağında zenginleşen As, Se, Cs, Sr, Sb ve Li elementler Özkul vd. (2017)'nin çalışmasın da belirtiği gibi borat yataklarının bulunmasinda iz bulucu element olarak kullanılabilir.

Şeyhler bölgesinde zenginleștiği belirlenen As, Se, Sr, Cs, Sb ve Li gibi elementlerden bazılarının ( $\mathrm{Se}$ ve $\mathrm{Li}$ gibi) yan ürün olarak kazanılması bu araştırmada önerilmektedir. Bunun için Ar-Ge çalışmalarına ihtiyaç vardır. Zenginleşen diğer elementler de bu kapsamda ele alınabilir. Böylece dünyada en çok Türkiye'de bulunan bor rezervlerinin daha ekonomik değerlendirmesi yapılmış olacaktır.

Elementlerin korelasyon cluster analizlerine göre, $\mathrm{Zr}, \mathrm{Nb}, \mathrm{K}, \mathrm{Rb}$, Th, Ti, Al, Si, NTE, Pb, P, $\mathrm{Li}, \mathrm{U}, \mathrm{Cs}, \mathrm{Cu}, \mathrm{Ba}, \mathrm{Fe}, \mathrm{Y}, \mathrm{TOT} / \mathrm{S}, \mathrm{Co}, \mathrm{Ni}, \mathrm{Mo}$, As, $\mathrm{Ag}, \mathrm{TOT} / \mathrm{C}, \mathrm{Mg}$ ve Sb birinci grup, Te, $\mathrm{Sr}, \mathrm{Se}, \mathrm{Ca}$, $\mathrm{Na}$ ve $\mathrm{B}_{2} \mathrm{O}_{3}$ elementlerinin oluşturduğu ikinci grup şeklindedir.

B'un kil grubunu temsil eden elementlerle negatif ilişki göstermesi borun kaynağının onlardan farklı olduğunu ve büyük oranda detritik olmadığını işaret etmektedir.

As, Cs, Sb ve Li kil grubu elementlerle, Se' un $\mathrm{Ca}$ ile Sr'un Te ile pozitif korelasyonu söz konusudur.

Emet Şeyhler bölgesinde Ce ve Eu negatif ve pozitif anomalisi söz konusudur. Şeyhler borat yatağının oluştuğu sedimanter ortamda, ortamın 
oksijenli olduğu, yüksek pH'lı hidrotermal suların borat oluşum sürecine katıldığı, kitasal kabuk katkısından ve düşük sıcaklıktan dolayı yeraltı suları ile yatay volkanik kayaçların az etkileştiği, bunun da negatif Eu anomalisini doğurduğu ileri sürülebilir.

Sonuç olarak; jeolojik veriler, baskın hidrotermal katkı, killere bağlı elementler, alkalen koşullarda oluşan minerallerin varlığı ve NTE anomalileri Emet Şeyhler borat yataklarının, volkanik ve karasal malzemelerle beslenen ve yüksek pH'lı playa göllerinde, kurak-yarı kurak iklim etkisindeki evaporasyon koşullar altında oluştuğu söylenebilir.

\section{EXTENDED SUMMARY}

Nearly $72 \%$ world's borate reserves are in western part of Turkey. Newly discovered Şeyhler (Emet, Kütahya) deposit is one of these deposits. The Şeyhler borate deposit, like other deposits in western Anatolia, was deposited in Miocene lacustrine environment whose formation coincides with volcanic activity that started in Paleogene and lasted until the beginning of Quaternary. All mineralizations are associated with volcanic activity. Most of boron is transported in the lacustrine environment by the agency of hyrothermal solutions during volcanic activitiy. The borate ore displaying lenticular structure is alternated with claystone, marl, tuff and thin bedded limestone. The mineral paragenesis is composed of colemanite, hydroboracite, ulexite, dolomite, calcite, cristobalite, scolecite, montmorillonite, and illite.

In the present study major and trace element contents of 18 borate samples from this deposit are discussed. The main element, Ca in Emet Sheyhler deposits is increased compared with the averages of Earth crust and common andesite. Among the trace elements, significant enrichment is determined in As, Se, Sr, Cs, Sb and Li. It can be concluded that based on the concentration of Se and Li elements could be recovered as by product, besides B. Element correlations indicate volcanic source for boron (exhalations and hydrothermal solutions) whilst other elements are found to be derived from a terrestrial source. According to REE data, Ce and Eu anomalies observed in the REE distribution diagrams showed that deposits formed under high oxygen and hydrothermal contribution.

\section{DEĞINILEN BELGELER}

Abollino, O., Aceto, M., Buoso, S., Gasparon, M., Green,W, J., Malandrino, M. and Mentasti, E., 2004. Distribution of major, minor and trace elements in lake environments of Antarctica. Antarctic Science, 16(3), 277-291.

Akdeniz, N. ve Konak, N., 1979. Simav - Emet Dursunbey - Demirci Yörelerinin Jeolojisi. MTA Derleme Raporu, No. 6547.108s.

Bau, M., 1991. Rare-earth element mobility during hydrothermal and metamorphic fluid rock interaction and the significance of the oxidation state of europium. Chemical Geology, 93 (3-4), 219-230.

Bence, A.E. and Taylor, B.E., 1985. Rare earth element systematics of West Shasta Metavolcanic Rocks: Petrogenesis and hydrothermal alteration. Economic Geology, 80(8), 2164-2176

Bhatia, M.R. 1985. Rare earth element geochemistry of Australian Paleozoic graywacks and mudrocks: Provenance and tectonic control. Sedimentary Geology, 45(1-2), 97- 113.

Boggs, S. 2009. Petrology of Sedimentary Rocks. Cambridge University Press, Cambridge, England. $600 \mathrm{p}$.

Canet, C., Prol-Ledesma, R.M., Proenza, J. A., RubioRamos, M.A., Forrest, M J., Torres-Vera, M.A. and Rodriguez-Diaz A., 2005. Mn-Ba-Hg mineralization at shallow submarine hydrothermal veins in Bahý'a Concepcio'n, Baja California Sur, Mexico. Chemical Geology, 224, 96- 112.

Cantrell, K.J. and Bryne R.H. 1987. Rare earth element complexation by carbonate and oxolate ions. Geochimica Cosmochimica Acta, 51, 597-605. 
Constantopoulos, J., 1988. Fluid inclusion and REE geochemistry of fluorite from south central Idaho. Economic Geology, 83(3), 626-636.

Cooper, M A., Hawthorne F. C., García-Veigas, J., Alcobé, X., Helvaci, C., Grew, E. S. and Ball, N. A. 2015. Fontarnauite, $(\mathrm{Na}, \mathrm{K})_{2}(\mathrm{Sr}, \mathrm{Ca})\left(\mathrm{SO}_{4}\right)$ $\left[\mathrm{B}_{5} \mathrm{O}_{8}(\mathrm{OH})\right]\left(\mathrm{H}_{2} \mathrm{O}\right)_{2}$, A New Sulfate-Borate Mineral From Doğanlar (Emet), Kütahya Province, Western Anatolia, Turkey. Canadian Mineralogist, $53,803-820$

Çolak, M., Helvaci, C. and Maggetti, M., 2000. Saponite from the Emet Colemanite Mines, Kütahya, Turkey. Clays and Clay Minerals 48(4), 409-423.

Dündar, A., Güngör, N., Gürsel, T., Özden, M. ve Özyeğin, E. 1986. Kütahya-Emet Bor Tuzu Yatağı Nihai Değerlendirme Raporu, MTA Raporu, 151s (yayımlanmamış)

Erdem, N. İ., 2010. Emet-Hisarcık(Kütahya) Bor Yataklanmasını Oluşturan Bor Minerallerinin Dağılımları, Jeokimyası ve Oluşum Ortamlarının İncelenmesi, Kocaeli Üniversitesi Fen Bilimleri Enstitüsü., Kocaeli, Yüksek Lisans Tezi, 58s (yayımlanmamış)

Fleet, H.J., Henderson, P. and Kepme, D.D.C. 1976. Rare earth element and related chemistry of some drilled Southern Indian Ocean basalts and volcanogenic sediments. Journal of Geophysical Research (JGR) 81, 4257-4268.

Floyd, P.A., Helvac1, C. and Mittwede, S.K., 1997. Geochemical Discrimination Of Volcanic Rocks Associated with Borate Deposits: an exploration tool? Journal of Geochemical Exploration, 60(3), 185-205.

Fee, J.A., Gaudette, H.E., Lyons, W.B. and Long, D.T. 1992. Rare earth element distribution in the Lake Tyrell groundwaters, Victoria, Australia. Chemical Geology, 96, 67-93.

Fu, X., Wang, J., Zeng, Y., Tan, F. and He, J., 2011. Geochemistry and origin of rare earth elements (REEs) in the Shengli River oil shale, northern Tibet, China. Chemie Der Erde-Geochemistry, 71(1), 21-30.

Gale G.H., Dabek L.B. and Fedikov, M.A.F., 1997. The application of rare earth element analyses in the exploration for volcanogenic massive sulphide deposites. Exploration and Mining Geology, 6(3), 233-252
García-Veigas, J., Rosell, L., Alcobé, X., Subias, I., Ortí, F., Gündoğan, I. and Helvacı, C., 2010a. Fontarnauite, a new sulphate-borate mineral from the Emet borate district (Turkey). Macla, 13, 9798.

García-Veigas, J., Ortí, F., Rosell L, Gündoğan, I. and Helvac1, C., 2010b. Occurrence of a new sulphate mineral: $\mathrm{Ca} 7 \mathrm{Na} 3 \mathrm{~K}(\mathrm{SO} 4) 9$ in the Emet borate deposits, western Anatolia (Turkey). Geological Quarterly, 54(4), 431-438.

García-Veigas, J., Ortí, F., Rosell L, Gündoğan, I. and Helvac1, C., 2011. Mineralogy, diagenesis and hydrochemical evolution in a probertiteglauberite-halite saline lake (Miocene, Emet Basin, Turkey). Chemical Geology, 280(3-4), 352-364.

Gawlik, J., 1956. Emet Kütahya Neojenindeki Borat Zuhuruna Ait Rapor, MTA Derleme Raporu, No:2479. (yayımlanmamış)

Graf, J.L.,1977. Rare earth elements as hydrothermal tracers during the formation of massive sulphide deposits in volcanic rocks, Economic Geology, 72(4), 527-548.

Habashi, F., 1997. Hanbook of Extractive Metallurgy. Wiley VCH. Weinheim. Germany. 2426p

Hatipoğlu, Z. N., 2010. Emet (Kütahya) Borat Havzası Volkanosedimanter Çökellerinin Mineralojisi ve Jeokimyası. Hacettepe Üniversitesi Fen Bilimleri Enstitüsü. Ankara, Yüksek Lisans Tezi, 115s (yayımlanmamış)

Helvac1, C. ve Firman, R.J., 1977. Emet Borat Yataklarının Jeolojik Konumu ve Mineralojisi. Jeoloji Mühendisliği Dergisi, 2, 17-29.

Helvaci, C. 1984. Occurrence of rare borate minerals: Veatchite-A, Tunellite, Teruggite and Cahnite in the Emet Borate Deposit, Turkey. Mineralium Deposita, 19 (3), 217-226.

Helvac1, C. and Orti, F. 1998. Sedimantology and diagenesis of Miocene colemanite-ulexite deposits (western Anatolia, Turkey). Journal of Sedimentary Research, 68(5),1021-1033.

Helvacı, C. 2003. Türkiye Borat Yatakları. Jeolojik Konumu, Ekonomik Önemi ve Bor Politikası. BAÜ Fen Bilimleri Enstitüsü Dergisi. 5(1) 4-41.

Helvacı, C. 2004. Türkiye Borat Yatakları. Jeolojik Konumu, Ekonomik Önemi ve Bor Politikasi. 5. Endüstriyel Hammaddeler Sempozyumu, 13-14 Mayıs, İzmir, Türkiye, s.11-27. 
Helvac1, C. 2015a. Geological Features of Neogene Basins Hosting Borate Deposits: An Overview of Deposits and Future Forecast, Turkey. Bulletin of the Mineral Research and Exploration, 151, 173219.

Helvac1, C. 2015b. Review of The Occurrence of Two New Minerals in The Emet Borate Deposit, Turkey: Emetite, $\mathrm{Ca}_{7} \mathrm{Na}_{3} \mathrm{~K}\left(\mathrm{SO}_{4}\right)_{9}$, and Fontarnauite, $\quad \mathrm{Na}_{2} \mathrm{Sr}\left(\mathrm{SO}_{4}\right)\left[\mathrm{B}_{5} \mathrm{O}_{8}(\mathrm{OH})\right]\left(\mathrm{H}_{2} \mathrm{O}\right)_{2}$. Bulletin of the Mineral Research and Exploration, 151, 273-287.

Henderson, P. 1984. Rare Earth Element Geochemistry. Devolopments in Geochemistry. Elsevier, Amsterdam, pp 317-347.

İlhan, A. 2006. Emet ve Hisarcık (Kütahya) Civarı Bor Yataklarının Mineralojik ve Jeokimyasal İncelenmesi. Ankara Üniversitesi Fen Bilimleri Enstitüsü. Ankara, Yüksek Lisans Tezi, 88s. (yayımlanmamış)

İnan, K. 1975. Sulu Bor Mineral Yataklarının Oluşumu, Türkiye Jeoloji Bülteni, 18(1-2), 165-168.

Johannesson, K.H., Lyons, W.B., Yelken, M.A., Gaudette, H.E. and Stetzenbach, K.J. 1996. Geochemistry of rare earth elements in hypersaline and dilute acidic natural terrestrial waters: Complexation behaviour and middle rare earth element enrichment. Chem. Geol., 133, 125-144.

Kamber B.S. and Webb G.E. 2001. The geochemistry of late Archaean microbial carbonate: implications for ocean chemistry and continental erosion history. Geochimica Cosmochimica Acta, 65(15):2509-2525

Kato, Y. and Isozaki, Y., 2009. $\square$ Comment on "Evaluation of palaeo-oxygenation of the ocean bottom cross the Permian-Triassic boundary" by Kakuwa (2008): Was the Late Permian deepsuperocean really oxic? Global and Planetary Change, 69(1-2), 79-81.

Koç, Ş., Kavrazlı, and Ö., Koçak, İ., 2008a. Geochemistry of colemanite deposit of Kestelek, Bursa, Turkey. 33rd. International Geological Congress, August 6-14th, Oslo, Norway, Abstracts MRB-01 (http:// www.cprm.gov.br/33IGC/1352424.html).

Koç, Ş., Koçak, İ. and Kavrazlı, Ö., 2008b. Trace Elements Concentrations of Colemanite in Kestelek Borate Deposit. 16th International Symposium on Boron, Borides and Related Materials, Matsue, Shimane, Japan, September 7-12, p.57-58.
Koç, Ş., Kavrazlı, Ö. and Koçak, İ., 2017. Geochemistry of Kestelek Colemanite Deposit, Bursa, Turkey. Journal of Earth Science, 28 (1), 63-77

Koçak, İ., 2014. Batı Anadolu Borat Yataklarının Jeokimyasal İncelenmesi. Ankara Üniversitesi Fen Bilimleri Enstitüsü. Ankara, Doktora Tezi, 318s. (yayımlanmamış)

Koçak, İ. and Koç, Ş., 2009. Trace element enrichment of Bigadiç Borates deposits, Balikesir, Turkiye. Goldschmidt Conference Abstracts 2009, June 22-26th, Davos, Switzerland. Geochimica Cosmochimica Acta, 73 (13), 671

Koçak, İ. and Koç, Ş., 2011. Trace Element Contents of Bigadiç and Kestelek Borate Deposits. 17th International Symposium on Boron Borides and Related Materials September 11-17, İstanbul, Turkey, p232

Koçak, İ. and Koç, Ş., 2012a. Major and Trace Element Geochemistry of the Bigadiç Borate Deposit, Balikesir, Turkey. Geochemistry İnternational, 50 (11), 926-951

Koçak, İ. ve Koç, Ş. 2012b. Kırka Borat Yatağında Zenginleşen Eser Elementler. V. Ulusal Jeokimya Sempozyumu, Bildiriler ve Özetler Kitabı, 23-25 Mayıs, Denizli, s.43-44.

Koçak, İ. and Koç, Ş., 2016. Geochemical characteristics of Kırka (Sarıkaya) borate deposit, northwestern Anatolia, Turkey. Journal of Earth System Science, 125 (1), p.147-164

Krauskopf, K.B., 1989. Introduction to Geochemistry. McGrow-Hill international editions, 617p.

Michard A. and Alberede F., 1986. The REE content of some hydrothermal fluids. Chemical Geology, 55, (1-2), 51-60.

McLennan, S.M., 1989. Rare Earth Elements in Sedimentary Rocks Influence of Provenance and Sedimentary Processes. Chapter in: Geochemistry and Mineralogy of Rare Earth Elements. B. R. Lipin and G.A. Mckay (Eds). Book Crafters, Michigan, 348 pp.

Nonce, W.B. and Taylor, S.R. 1977. Rare earth patterns and crustal evoluation. II. Archean Sedimentary Rocks from Kalgoorlie, Australia. Geochimica Cosmochimica Acta, 41(2), 225-231.

Nozaki Y., Zhang J. and Amakawa H. 1997. The fractionation between $\mathrm{Y}$ and Ho in the marine environment. Earth and Planetary Science Letters, 148, 329-340. 
Özkul, C. 2008. Emet (Kütahya) Neojen Havzası Bor Prospeksiyonu: Hedef Saptamada Jeokimyasal Yöntem Geliştirme, Kocaeli Üniversitesi, Fen Bilimleri Enstitüsü. Kocaeli, Doktora Tezi, 158s. (yayımlanmamış)

Özkul C., Çiftçi, E., Tokel, S., and Savaş M., 2017. Boron as an exploration tool for Terrestrial Borate Deposits: A soil geochemical study in Neogene Emet-Hisarckk Basin Where the World Largest Borate Deposits Occur (Kütahya-Western Turkey). Journal of Geochemical Exploration, 173, 31-51

Özpeker, İ. 1969. Batı Anadolu Borat Yataklarının Mukayeseli Jenetik Etüdü, İTÜ Fen Bilimleri Enstitüsü. Doktora Tezi, İstanbul, 116s. (yayımlanmamış)

Sant'Anna, L.G., Clauer, N., Cordani, U.G., Riccomini, C., Velázquez, V.F. and Liewig, N. 2005. Origin and migration timing of hydrothermal fluids in sedimentary rocks of the Paraná Basin, South America. Chemical Geology, pp., 1-21.

Schroll, E., 1975. Analytische Geochemie. Ferdinand Enke Verlag, Stuttgart, 292p.

Sverjensky, D. A., 1984, Europium redox equilibria in aqueous solution. Earth Planet Science Lettters, 67(1), 70-78.

Şahinci, A. 1991. Doğal Suların Jeokimyası, Reform Matbaas1, 548s, İzmir.

Şaşmaz A., Türkyılmaz, B., Öztürk, N., Yavuz, C. and Kumral, M., 2014. Geology and Geochemistry of Middle Eocene Maden Complex Ferromanganese Deposits from Elazığ-Malatya Region, Eastern, Turkey. Ore Geology Reviews, 56, 352-372.

Taylor, S.R. and McLennan, S.M., 1985. The Continental Crust: Its Composition and Evolution. Blackwell, Oxford, 312 p.
Usui, A. and Mita, N., 1995. Geochemistry and mineralogy of a modern buserite deposit from a hot spring in Hokkaido, Japan. Clay and Clays Minerals, 43(1), 116-127.

Weill, D.F. and Drake, M.J. 1973. Europium Anomaly in Plagioclase Feldspar: Experimental Results and Semi quantitative Model. Science, 180 (4090), 1059-1060.

Wright, J., Schrader, H. and Holser, W.T. 1987. Paletedox variations in ancient oceans recorded by rare earth elements in fossil apatite. Geochim. Cosmochim. Acta, 51(3), 631-644.

Yalçın, H. 1984. Emet Neojen Gölsel Baseninin Jeolojik ve Mineralojik-Petrografik İncelenmesi, Hacettepe Üniversitesi Fen Bilimleri Enstitüsü. Ankara, Yüksek Mühendislik Tezi, 198 s (yayımlanmamış)

Yalçın, H., Semelin, B. ve Gündoğdu, M.N. 1985. Emet gölsel Neojen baseninin jeolojik incelenmesi (Hisarcık güneyi). H. Ü. Yerbilimleri Dergisi, 12, $39-52$.

Yalçın, H., Gündoğdu, M.N. 1985. Emet gölsel Neojen baseninin kil mineralojisi. II. Ulusal Kil Sempozyumu, H.Ü. Beytepe-Ankara, 24-27 Eylül, Bildiriler Kitabı (Eds. M.N. Gündoğdu ve H. Aksoy), 155-170.

Yalçın, H. ve Gündoğdu, M. N., 1987. Neojen yaşlı Emet gölsel volkanosedimanter baseninin mineralojikpetrografik incelenmesi: Neoformasyon minerallerinin oluşumu ve dağılımı. H.Ü. Yerbilimleri Dergisi, 14, 45 -61. 